\title{
Releaser-induced recognition learning by amphibians and reptiles
}

\author{
MILTON D. SUBOSKI \\ Queen's University, Kingston, Ontario, Canada
}

\begin{abstract}
This review evaluates the bases of the widely held assumption that amphibians and reptiles possess impoverished learning abilities. Procedurally defined forms of learning (instrumental conditioning, Pavlovian conditioning and autoshaping, imprinting, and social learning) are reviewed, as well as evidence for the involvement of learning in various behavioral phenomena, including aversive stimulus and predator avoidance, noxious and palatable food recognition, conditioned aversion formation, search image, conspecific recognition, habitat recognition, and cultural transmission of stimulus recognition. The evidence reviewed suggests that amphibian and reptilian learning, for the most part, consists of a releasing-stimulus-induced redirection of innately organized released responses. Amphibians and reptiles appear to learn what stimulus to respond to rather than how to respond to a particular stimulus.
\end{abstract}

Amphibians and reptiles have often been viewed as providing little scope for the operation of learning processes. For example, Brattstrom (1974) noted that "in contrast to fish, birds, and mammals, reptiles are generally considered to lack complexity in all aspects of their behavior' (p. 35). Indeed, in traditional learning tasks, reptile and amphibian behavior has been quite resistant to modification by individual experience (e.g., Hodos \& Campbell, 1969; see also Burghardt, 1977, and Ellins, Cramer, \& Martin, 1982). One possible explanation is that much amphibian and reptilian behavior may occur as the result of unlearned responses to releasing stimuli. For example, newborns of conspecific and congeneric snakes show strong initial preferences for their parental diets (Arnold, 1981; Burghardt, 1968; see also Dix, 1968 ), even to the point of starving in the presence of food that is immediately accepted and preferred by another race of conspecifics (Arnold, 1981).

A second possible explanation for many failures to find strong evidence of learning may be that learning models inappropriate to the behavior of amphibians and reptiles have nevertheless dictated the experimental procedures. The four most important learning models are procedurally defined; that is, these models specify the experimental procedures necessary to produce learned behavior change in animals. Of the four models, only Pavlovian (classical) and operant (instrumental) conditioning are presumed to be general models applicable to all (or much) infrahuman learned behavior. The third model, imprinting, was proposed for learning the characteristics of a single stimu-

\footnotetext{
Preparation of this paper was supported in part by grants from the Advisory Research Committee of Queen's University and the Natural Sciences and Engineering Research Council of Canada (Grant A-7059). Correspondence should be addressed to Milton D. Suboski, 18 Cunliffe Close, Oxford OX2 7BL, England.
}

lus or unitary object as a result of simple exposure to the object. The fourth model, social learning, is relevant to learned behavior change that is dependent on interaction among conspecifics. The imprinting and social learning models have been but rarely invoked in explanation of amphibian or reptile behavior, and they have been further considered only in the context of discussion of particular learning phenomena.

The difficulties encountered in formal applications of procedural learning models are apparent from a brief overview. Most investigations of learning in amphibians and reptiles have been inspired by the instrumental (operant) conditioning model, wherein reinforcement (and hence learning) is assumed to result when the application or removal of particular stimuli is more contingent on production of the desired behavior by the animal. The outcomes of such studies may justify the conclusion that operant conditioning does occur in amphibians and reptiles, although the control over behavior obtained thereby is often drastically inferior to that found in other vertebrate classes (see, e.g., Bitterman, 1964; Burghardt, 1977; Ellins et al., 1982; Pert \& Bitterman, 1969; Thompson \& Boice, 1975). In fact, much of the behavior of amphibians and reptiles has proven to be relatively unresponsive to modification by typical positive and negative reinforcers. Unresponsiveness to food, the primary positive reinforcer, is often attributed to the limited effects of deprivation on lethargic animals that feed infrequently. Unresponsiveness to aversive electric shock is less easily understood.

The other general learning model, Pavlovian conditioning, has been formally applied to amphibians and reptiles surprisingly seldom (see, e.g., R. E. Davidson \& Richardson, 1970; Farris \& Breuning, 1977; Goldstein, Spies, \& Sepinwall, 1964; Yaremko, Boice, \& Thompson, 1969; Zavala, 1968). The paucity of Pavlovian studies is particularly noteworthy, since classical conditioning is often viewed as a very general and simple process that under- 
lies many higher forms of learning (see, e.g., Hawkins \& Kandel, 1984).

\section{RELEASER-INDUCED RECOGNITION LEARNING}

The present review is concerned with the possibility that a more relevant learning model could reveal that learning plays a larger role in the behavior of amphibians and reptiles than has hitherto been suspected. The model, termed releaser-induced recognition learning (Suboski, $1988,1989,1990$ ), combines the concept of releasingstimulus-released-response interactions from classical ethology with the transfer-of-control version of the stimulus substitution principle from Pavlovian conditioning. The essential features of the model will be briefly described here; this will be followed by a review of the extent to which the releaser-induced model can provide a plausible general mechanism for amphibian and reptilian learning.

The releaser-induced recognition model agrees with the overall structure of the Pavlovian conditioning model in viewing learning as a product of a relationship between two stimuli, one of which is initially response neutral and the other initially response eliciting. However, the models are distinguishable in a number of important ways. The first dissimilarity is a matter of practice rather than principle. In the Pavlovian procedure, unconditioned stimuli (USs) are usually selected to elicit relatively simple, reflexive types of behavior. In contrast, the releaser-induced recognition model assumes that Pavlovian USs are a limited subset of a broader class of unlearned releasing stimuli that, under natural conditions, elicit phylogenetically preorganized sequences of released responses. In this respect, the releaser-induced recognition model is similar to the autoshaping version of Pavlovian conditioning.

A second important premise of the releaser-induced learning model is that the basic mechanism underlying learning is the transfer-of-control version of Pavlovian stimulus substitution theory (see Hearst \& Jenkins, 1974; Suboski, 1988, 1990) and does not involve any concept of reinforcement. According to one version of stimulus substitution theory, the Pavlovian conditioning procedure results in a conditioned animal that responds to the conditioned stimulus (CS) as if it were the US; the CS serves as a surrogate for the US. The transfer-of-control version differs by holding that the CS simply acquires an ability to elicit as conditioned responses (CRs) from an animal the same responses that the US elicited as unconditioned responses (URs). The resultant learning, termed releasingvalence transfer, provides a means by which control over the ability of an animal to recognize and appropriately respond to a stimulus can be transferred from one stimulus to another. The mechanism permits phylogenetically acquired and organized recognition of environmentally invariant stimuli to mediate individually acquired recognition of environmentally variable stimuli (cf. Burghardt, 1977, p. 560; Ewert, 1980, pp. 58 and 124; Lorenz,
1969; Schöne, 1964; see also Thorndike, 1935, on "associative shifting," pp. 191-197).

A third distinguishing feature of releaser-induced recognition learning concerns the taxic direction of released responses. Although some released responses are essentially directionless (ataxic), most released responses are directed with respect to the eliciting stimulus. Thus, animals approach, contact, and direct consummatory responses to some stimuli (autotaxic releasers), whereas they engage in withdrawal, escape, and avoidance behavior in response to other stimuli (antitaxic releasers). Allotaxic releasers, frequently found in social interactions, are less well recognized. Releasing stimuli provided by a conspecific instigator often result from behavior (e.g., eating, alarm) directed toward a stimulus object (e.g., a novel food, a predator). The responses released from the reacting animal may be directed, not at or away from the instigating conspecific, but toward or away from the stimulus object. Thus, an allotaxic releasing stimulus directs behavior of an observer animal with respect to a stimulus other than the releaser itself.

A major premise of the releaser-induced learning model is that control over the taxic direction of released responses is intrinsic to releasing valence and, in Pavlovian conditioning terms, is transferred from US to CS just as the ability of the CS to elicit CRs is induced from the ability of the US to elicit URs. In social interactions, biologically important behaviors (feeding, alarm, etc.) specifically directed toward or away from particular environmental stimuli may be positive or negative allotaxic releasers. If so, responses of observing conspecifics may subsequently be similarly released and positively or negatively directed by similar environmental stimuli.

\section{LEARNED BEHAVIOR OF AMPHIBIANS AND REPTILES}

In addition to Pavlovian conditioning and autoshaping, and instrumental conditioning, the phenomena interpretable as forms of releaser-induced recognition that have been found in reptiles and/or amphibians include aversive stimulus, predator, and unpalatable food recognition; search image formation and food imprinting; long-delay conditioned aversions; and sibling recognition; they may include other kinds of conspecific recognition such as mate, neighbor, and, quite likely, territory or habitat recognition. Releaser-induced recognition forms of cultural or social transmission of stimulus recognition are prominent in the behavior of birds and mammals and may be found in fish (Suboski, 1988), but they have been little considered in amphibians or reptiles (see Boyden, 1976; N. Greenberg, 1976). Spatial orientation and navigation are common, complex features of amphibian and reptilian recognition behavior (see, e.g., De Rosa \& Taylor, 1982; Ferguson, Landreth, \& McKeown, 1967; Landreth \& Ferguson, 1968; Murphy, 1981). Although such phenomena are quite likely dependent on the operation of mecha- 
nisms similar to releaser-induced recognition, their complexity currently defies analysis and will not be further discussed.

\section{Pavlovian Conditioning and Autoshaping}

Pavlovian conditioning is an interesting and ubiquitous phenomenon often cited as if it provided an explanatory mechanism for specific manifestations of conditioning. However, as Gormezano and Kehoe (1975, p. 146) noted, Pavlovian conditioning is itself a phenomenon in need of explanation. Pavlovian conditioning and releaser-induced recognition learning clearly reflect the same underlying mechanism and thus should not make any mutually contradictory predictions. If the operative mechanism is in fact the transfer-of-control version of stimulus substitution, both models would predict CRs and URs to be similar in form. In any case, theoretical interpretation may be somewhat premature, since traditional Pavlovian conditioning has barely been demonstrated in amphibians and reptiles and then only with aversive USs.

In an early formal Pavlovian study, Goldstein et al. (1964) used a light touch to the cornea as the US in conditioning of eyelid closure in leopard frogs (Rana pipiens). An apparently normal acquisition function - that is, a gradual increase in CR frequency over trials to a respectable level (66\% CRs)-was obtained along with typical extinction and relearning effects. Eyelid closures, $95 \%$ all-ornone in form according to Goldstein et al. (1964), constituted both CRs and URs. Interpretation of this study as a successful demonstration of Pavlovian conditioning is clouded by the failure of Yaremko et al. (1969) to find comparable conditioning effects despite the use of similar subjects ( $R$. pipiens) and procedures (see also Franzisket, 1963, and Kimble \& Ray, 1965). Yaremko et al. (1969) went on to report that they had successfully conditioned toads (Bufo americanus) by using exactly the same procedures as those that failed to produce conditioning in frogs.

Zavala (1968) presented a bubbling-water CS paired with an electric shock US to $R$. pipiens. The CRs were leg or body movements (of unspecified magnitude), but UR form was unmentioned. The results-terminal levels of $30 \%$ CRs for the conditioning group as compared to $10 \%$ CRs for a control group that received the CS and US unpaired-were unimpressive and unevaluated for reliability, despite small sample sizes $(N s=3)$. R. E. Davidson and Richardson (1970) recorded pulse rate, respiration, and leg movement during classical conditioning of collared lizards (Crotaphytus collaris) to an electric shock US. Measurement of responses during the 10-sec period prior to the $10-\sec C S$ was the only control condition for the small $(N=4)$ conditioned group, and prolonged conditioning was required for subjects to reach $80 \%$ CRs. All of the variables measured were bidirectional; but the direction of change in the URs was unmentioned, and the direction of change in the CRs was apparently designated on the basis of the predominant direction of change to the CS during conditioning. Most recently, Farris and Breuning (1977) conditioned head withdrawal in the red-eared turtle (Chrysemys scripta elegans) by using a hammer blow to the anterior carapace as the US. In this study also, no controls were included and $N(4)$ was small, but the CR and UR were clearly the same response.

Traditional Pavlovian conditioning studies with an appetitive (reward) US are notable for their absence. There are a variety of possibly good reasons for this, including habits of infrequent feeding among some reptiles and amphibians and a general lack of well-developed simple preparations for appetitive Pavlovian conditioning. Nevertheless, it is quite likely that Pavlovian conditioning occurs in these animals, as has been attested by the single formal demonstration of appetitive autoshaping (Loop, 1976), conducted on Bengal monitor lizards, Varanus bengalensis. Illumination of a response key signaled presentation of dead mouse pups to lizards. Despite the lack of any contingency save temporal prediction between response key illumination and mouse pup delivery, each of the four lizards showed selectively increased responding to the key when it was illuminated. Although control conditions were again absent, the study is particularly interesting because the autoshaped responses were consummatory responses appropriate to the US: "observation of the animals revealed that responses were the result of open mouthed bites or pecks directed at the CS"' (Loop, 1976, p. 575).

Appetitive and consummatory responses directed at the CS have been repeatedly observed when the autoshaping procedure has been inadvertently included in some other paradigm. The report by Van Bergeijk (1967) that bullfrogs, $R$. catesbeiana, would congregate around the feeding trough starting several hours in advance of the fixed daily feeding time belongs in this category. The behavior was under control of external stimuli, since the frogs failed to congregate on weekends and holidays when stimulus conditions were different from those on working days. Furthermore, the area of congregation changed appropriately when the feeding area was changed.

Similar reports of anticipatory orientation responses to stimulus cues associated with feeding have been reported for other amphibians-the American toad (B. americanus, Boice, Quanty, \& Williams, 1974), the common toad (B. bufo bufo, Brzoska \& Schneider, 1978), and a salamander (Ambystoma paroticum, Moore \& Welch, 1940) - and for reptiles: the western painted turtle (Chrysemys marginata, Casteel, 1911), a wood turtle (Clemmys insculpta, Tinklepaugh, 1932), a red-eared turtle (Pseudemys scripta troostii, Murillo, Diercks, \& Capaldi, 1961), the British viper (Vipera berus, Appleby, 1971, p. 29), the Sonoran gopher snake (Pituophis catenifer affinis, Greenwald, 1974), and the American alligator ( $\mathrm{Al}$ ligator mississippiensis, R. S. Davidson, 1966). These observations could easily be, and often have been, attributed to appetitive instrumental conditioning, since the effect of the anticipatory behaviors is to position the animal favor- 
ably for the receipt of food. However, such interpretation suffers from the fact that the food is typically almost immediately available regardless of the animal's placement.

Releaser-induced transfer-of-control effects have also been observed in instrumental discrimination conditioning with food or other reward for responses to one stimulus $(\mathrm{S}+)$ and either no reward or punishment for responses to the other stimulus (S-). Kuroda (1933) reported that 3 of 9 turtles, Clemmys japonica, trained in a discrimination learning task, were observed to snap at $\mathrm{S}+$ as if it were food. Apparently similar observations were reported for the sand lizard, Lacerta agilis, by Świeźawska (1949). Casteel (1911) noted that 1 of 7 painted turtles, Chrysemys marginata, trained on visual discrimination tasks almost invariably stopped on entering the goalbox and bit the blind that hid the food. Mlynarski (1951) described behavior of 1 of 5 Emydinae turtles as endeavoring with curious obstinacy to catch the cards with the training figures.

The evidence that consummatory responses are directed toward discriminative stimuli suggests an alternative explanation for the effectiveness of food "baiting" of manipulanda (Bitterman, 1964; Pert \& Bitterman, 1969) or positive discriminative stimuli (Holmes \& Bitterman, 1966; Pritz, Bass, \& Northcutt, 1973) in training apparently instrumental responses. The instrumental explanation is simply that responding to food on $\mathrm{S}+$ or the manipulandum exposes the animal to the response-reinforcer contingency more quickly. The transfer-of-control explanation is that an increase in the spatial and/or temporal proximity between precursor stimuli and consummatory stimuli by baiting will enhance the transfer of control over the release of consummatory responses to precursor stimuli.

In general, stimuli selectively associated with food appear to acquire releasing valence to elicit approach and consummatory behavior. Although readily interpretable as manifestations of releaser-induced learning, such effects are often not clearly classifiable as Pavlovian or instrumental conditioning on the basis of procedural criteria. For example, toads, Bufo boreas, approach and direct feeding responses selectively to odor stimuli from prey that they have previously ingested in preference to odors from novel prey (Dole, Rose, \& Tachiki, 1981). Similarly, postmetamorphic salamanders, Ambystoma texanum, were reported to approach forceps that had been used to feed them when they were larvae (Brandt, 1947; see Flower, 1927). Burghardt (1969) observed that neonatal snakes of genus Thamnophis would increase tongue flicking in response to blank distilled water swabs when the presentation of such swabs had been preceded by prey extract swabs that did elicit attacks.

The evidence reviewed here indicates that Pavlovian conditioning with a food US activates a mechanism by which control over feeding responses is transferred from interoceptive (gustatory, postingestional), typical US stimuli, to exteroceptive (visual, olfactory), typical CS cues. Furthermore, instrumental conditioning and reinforcement processes are not required to explain the evidence for Pavlovian conditioning reviewed here. Transfer of stimulus control over the release of innately organized feeding behavior alone satisfactorily accounts for learned food recognition in amphibians and reptiles.

\section{Instrumental Conditioning: \\ Aversive Stimulus/Predator Avoidance}

Instrumental learning, according to current views, is manifested by changes in the frequency of arbitrarily selected responses as a result of response-contingent application or removal of appetitive or aversive reinforcing stimuli. The principle of equipotentiality of responses contained in this description is an essential feature of reinforcementbased instrumental conditioning despite the exceptions attested to by large differences in the conditionability of various arbitrary response-reinforcer combinations.

According to the contrasting interpretation from the releaser-induced learning model, the mechanism underlying at least simple instances of instrumental conditioning does not differ from that underlying Pavlovian conditioning. Instrumental reinforcers, like Pavlovian USs, are seen as valence-inducing releasing stimuli that elicit phylogenetically prepared responses and transfer control over the elicitation of such responses, usually to temporally preceding stimuli. From this view, the responses that occur in instrumental conditioning are not expected to be arbitrary in form, but rather are selected from what may be a large class of responses (e.g., general food seeking and antipredator behaviors) relevant to the biological process subserved by the reinforcer. The reinforcement model also predicts that only specifically or inadvertently reinforced responses will change in frequency during conditioning. Again, releaser-induced learning expects occurrence of responses relevant to the biological process activated by the releaser.

Contrary to expectations from reinforcement theory, conventional reinforcers (food, painful electric shock) are often found to be ineffective in the conditioning of arbitrary responses in amphibians and reptiles. These problems have had a number of different effects, including (1) a paucity of investigations that have used food reinforcers alone (see Chu \& McCain, 1969), (2) meager and inconsistent evidence of learning reported in the more numerous accounts of escape and avoidance conditioning reinforced with aversive stimuli, (3) frequent use of unconventional reinforcers, such as heat and light, and (4) many studies that were conducted with the limited purpose of demonstrating learning in a particular species, typically using only a single group of the animals.

As noted by Northcutt and Heath (1973), the conclusion that a procedure has produced learning is often based solely on the nature and direction of the changes in behavior that occur with increased amounts of training of a single group. If the changes are consistent with the presumed effects of reinforcement-that is, decreased time to complete the task, fewer errors, faster reversals in discrimination, and so forth-then the changes in behavior are attributed to the occurrence of instrumental conditioning. The perils of this process are clearly shown in a report by 
McGill (1960). McGill attempted to train frogs (R. pipiens) to escape aversive electric shock by shuttling back and forth in a two-compartment apparatus. Although it became apparent soon afterward that McGill's procedures would have rendered the task difficult for rats and other mammals (see, e.g., Theios \& Dunaway, 1964), the data were nonetheless remarkable. From the very first trial, the escape performance of the frogs deteriorated steadily despite temporary decreases in escape latency produced by periodic increases in shock intensity. Eventually, escape ceased entirely and all 7 frogs died. McGill concluded that, maladaptively, "the animals learned that a reduction in activity resulted in a reduction of discomfort from the shock' (McGill, 1960, p. 445), a conclusion readily accepted by others (e.g., Harvey, Ellis, \& Tate, 1976; Ray, 1970).

Apart from demonstrating the powerful appeal of reinforcement theory as a putative explanatory mechanism, McGill's (1960) study provides a focus for a discussion of the role of learning in the acquisition of defensive behaviors. Frogs (in particular $R$. pipiens) have long been recalcitrant subjects for aversive instrumental conditioning (Boice, 1970: $R$. pipiens, $R$. clamitans; Greding, 1971: $R$. pipiens, $R$. clamitans, $R$. boylii; Hoyer, 1973: $R$. pipiens; Hoyer, Shafer, Mauldin, \& Corbett, 1971: $R$. pipiens; Kleerekoper \& Sibabin, 1959: $R$. pipiens, R. clamitans; Miller \& Berk, 1977: Xenopus laevis; Miller, Berk, \& Springer, 1974: X. laevis; Munn, 1940: $R$. catesbeiana, Hyla versicolor, $H$. cinerea; Smith, 1948: Acris gryllus dorsalis; Thompson \& Boice, 1975: $R$. pipiens; Yaremko et al., 1969: $R$. pipiens; Yerkes, 1903: $R$. clamitans), even in comparison with toads (Boice, 1970; Yaremko, Jette, \& Utter, 1974: B. woodhousei, Scaphiopus hammondi; Greding, 1971: B. marinus, B. valliceps, B. woodhousii fowleri; Yaremko et al., 1969: B. americanus).

These studies have repeatedly demonstrated that escape and avoidance responses arbitrarily selected by an experimenter are apparently not those used by most frogs to escape or avoid a noxious stimulus. In fact, regardless of the instrumental contingencies that have been arranged, only one behavior, freezing, consistently increases in frequency with increases in training of frogs. Thompson and Boice (1975) pointed out that immobility might be the main species-specific defensive response (SSDR; Bolles, 1970) of frogs to electric shock. Bolles contended that SSDRs are not usually learned but rather are immediately manifested as unlearned reactions to cues from real or potential predators. According to Bolles, when noxious stimuli are encountered by an animal, its behavior is severely restricted to SSDRs. An avoidance response "can be rapidly acquired only if it is an SSDR" and "is rapidly acquired only by the suppression of other SSDRs" (Bolles, 1970 , p. 34; italics in original). Presumably, SSDRs are acquired as escape or avoidance responses, not because of reinforcement from shock elimination, but rather because other SSDRs that do not result in shock elimination are suppressed by punishment.
Bolles's (1970) explanation may work very well for escape and avoidance learning (or a lack thereof) by frogs. Of the SSDRs available to frogs, none appears to satisfy the escape and avoidance contingencies arbitrarily established in shock avoidance tasks. All SSDRs are thus equally ineffective and equally punished, with immobility remaining the most frequent SSDR. The hapless frog is a helpless victim of SSDRs that are ecologically effective in the natural environment but not in the shock box.

The releaser-induced recognition learning model agrees with the essence of Bolles's (1970) interpretation. Clearly, SSDRs are released responses with antipredator function. The main difference between the two accounts lies in the mechanism hypothesized for acquisition of avoidance behavior. Bolles proposed that ineffective SSDRs are suppressed by punishment (also see Bolles's safety signal effect). Releaser-induced recognition learning proposes a two-phase mechanism that begins by noting that releasing stimuli for SSDRs other than freezing elicit locomotory behavior directed away from (antitaxic to) the releasing stimuli. (Almost all avoidance contingencies require experimental subjects to approach the CS/predator cues; see Biederman, D'Amato, \& Keller, 1964.) Upon the occurrence of a releasing stimulus for an SSDR, any other available stimulus that can help to locate, in time or space, the predator or other source of the original releasing stimuli will acquire control over the release and direction of the SSDR. The mechanism is simply an intraindividual transfer of control over the release and stimulus direction of an SSDR from original releasing stimuli to originally neutral but predictive stimuli. The transfer-ofcontrol mechanism has a role in the second phase of avoidance acquisition as well. When escape by an animal terminates releasing stimuli, concurrent neutral stimuli may also receive transferred control over the release of further SSDRs. The difference is that in the second phase, transferred control over escape SSDRs will be autotaxic-that is, they will consist of movement toward the neutral stimuli that accompanied escape.

This account of avoidance response acquisition has several advantages over reinforcement theory in explanatory parsimony. First, none of the problems of reinforcement theory affect the present interpretation in which reinforcement is, at best, an effect rather than a cause. Second, no explanatory baggage is required to show how avoidance responses can be reinforced by the absence of a stimulus. Finally, anthropomorphic constructs such as "fear" need not be invoked.

Unfortunately, the problem of explaining the failure of frogs to learn escape and avoidance responses is not solved by simply hypothesizing interference from SSDRs of freezing. Bolles (1970) emphasized the role of novel and sudden events in releasing general SSDRs such as flight, freezing, or threat. However, both SSDRs and the stimuli that release them may be highly specific, not only to the given species but also to predator type, distance from frog to predator, and location of safer areas (often water). It is not the case that frogs, particularly Rana species and 
specifically $R$. pipiens, always freeze in response to predator cues. Certainly the dominant response to the approach of a terrestrial predator by frogs of many species is to leap away, often into or away from water. It has been abundantly shown (Jaeger \& Hailman, 1973) that many frog species are positively phototaxic. Given the opportunity, frogs of most species (87\% of 121 species; see Jaeger \& Hailman, 1973) will leap toward a large, brightly lighted area, particularly if it is blue in color. Despite unresolved questions concerning the ecological significance of positive phototaxis and blue preference (see, e.g. , Jaeger \& Hailman, 1973, 1976; Muntz, 1962) in obligatorily aquatic, nocturnal, or completely terrestrial species of frogs, the phototaxic behaviors occur when captured frogs are released from restraint and are almost certainly antipredator escape responses.

The form of the active escape response within species has surprisingly little variability among individuals, whereas large differences in SSDR form may be found between even very closely related species. Frogs do not jump randomly in a protean defense (Humphries \& Driver, 1970) but rather display species-specific fixed action patterns. Gans and Parsons (1966) noted that frogs of various species "evince characteristic multiple jump sequences, stereotyped in the number of components, the distance covered, and the directional changes between jumps" (p. 97). The Florida cricket frog, A. gryllus, was divided into two subspecies, $A$. gryllus gryllus and $A$. $g r y l-$ lus dorsalis, in large part on the basis of substantial differences in their leaping patterns during escape responding (Netting \& Goin, 1945). Similar differences were observed by Licht (1986; see also Herzog \& Burghardt, $1974)$ in two sympatric species of congeneric frogs ( $R$. aurora, $R$. pretiosa). Frogs of both species flee by jumping when approached by a large terrestrial predator, but the nature and direction of the jumps differ in the two species. $R$. aurora make three to eight high, long leaps in a straight line on land and then seek cover in the vegetation. $R$. pretiosa make short, low jumps either toward water or in a circular route if water is not encountered.

Frogs of Rana species do freeze in response to the immediate presence of garter snakes (Thamnophis species; see Gregory, 1979; Licht, 1986). Freezing is undoubtedly adaptive in such circumstances, since the snakes appear incapable of visually locating a motionless frog (Gregory, 1979; Licht, 1986; see also Herzog \& Burghardt, 1974). Some snakes can identify prey by chemical cues provided from tongue flicking (Dowdey \& Brodie, 1989; Ducey \& Brodie, 1983). Garter snakes can probably find frogs in this way, since frogs remain flattened on the ground in the presence of a snake and do not jump until a snake is very near ( $<2 \mathrm{~cm}$; Licht, 1986). Snakes attack immediately following detection of a frog by tongue flicking, so frogs are likely to be acutely responsive to stimulus cues arising from being tongue flicked. Such sensitivity may help to account for the effectiveness of prodding frogs in inducing them to jump (see, e.g., Jaeger \& Hailman, 1973). As well, an electric shock may release
SSDRs normally activated in frogs by tongue flicks. In fact, McGill's (1960) frogs initially displayed leaping responses to shock onset, although these responses ceased over the first few training sessions.

The conclusion of this discussion of antipredator behavior of frogs is that maybe frogs really do learn absolutely nothing about predator avoidance, as Bolles (1970) has suggested. Certainly most predator avoidance behavior by frogs is unlearned. Indeed, SSDRs sometimes appear to interfere with arbitrary response learning by frogs (Kleerekoper \& Sibabin, 1959; McGill, 1960; Thompson \& Boice, 1975; Yerkes, 1903). If any learning is involved, it almost certainly is of a type easily accommodated by the releaser-induced learning model. To demonstrate such learning, a neutral stimulus-illumination of a light, perhaps-is presented to a frog along with predator cues-tongue flicking and possibly even electric shock. The frog is then tested in a natural arena large enough to permit SSDRs to occur. The releaser-induced learning model would expect the initially neutral stimulus to acquire the ability to release predator-escape behavior appropriate to the species and population of the frog. The procedure is Pavlovian, not operant; the mechanism is transfer of control, not reinforcement; the outcome is acquisition of stimulus recognition and appropriate response, not acquisition of an arbitrary response (Yaremko et al., 1974).

In contrast to results from adult frogs, larval $R$. pipiens have displayed moderate amounts of avoidance responding (40\% avoidance, Hoyer, $1973 ; 24 \%$, Hoyer et al., 1971 ) in a simple avoidance task. Tadpoles were placed in a circular water-filled chamber. Illumination of an overhead light served as an $\mathrm{S}+$, followed in $10 \mathrm{sec}$ by an electric shock if no avoidance occurred. The avoidance response was a forward movement of about $5 \mathrm{~cm}$. Several features suggest that this task should facilitate apparent avoidance learning. First, the avoidance response that is required is consistent with an SSDR of flight; second, the avoidance response does not require the tadpole to approach the aversive $S+$. In the natural environment, predator cues (S+ here) will mostly emanate from the predator itself; approaching such cues is unlikely to be adaptive.

An unusual form of antipredator behavior, found in the larvae of some species of frogs (Altig \& Christensen, 1981; Hews, 1988; Hews \& Blaustein, 1985) and toads (Hrbáček, 1950; Richmond, 1947), has been termed the "alarm" or "fright" reaction. Injury to the skin of tadpoles spills putative "alarm substance" into the surrounding water, where it releases a fright reaction in exposed conspecifics. The fright reaction-chaotic flight, sinking to the bottom, and so forth-probably has value in the avoidance of predation (Hews, 1988). However, alarm reactions would have far greater value if alarm substance produced releaser-induced predator recognition in anurans as it does in fish (Suboski et al., 1990). It may in fact do so; the issue has not yet been examined.

Antipredator defensive behavior differs somewhat between frogs and toads but follows the same general pat- 
tern. One difference is that bufonid toads have fewer predators because they contain highly toxic substances that render them unpalatable to most predators. Although some predators quickly learn not to feed on toads and other unpalatable prey (see, e.g., Brodie \& Formanowicz, 1987; Dodd \& Brodie, 1976; Johnson \& Brodie, 1975; Kruse \& Stone, 1984), some snakes, notably Thamnophis species, readily feed on toads. A second possible source of differences in SSDRs is that toads do not match frogs in the ability to make long rapid jumps to cover. Nevertheless, Hayes (1989) suggested that, as for frogs, "hopping toward cover is probably the initial escape response of most toads when approached by large vertebrate predators" (p. 1014; see also Bragg, 1945).

The behavior of toads toward the immediate presence of a recognized snake is quite similar to the behavior of frogs in the same situation. Like frogs, toads become immobile and may crouch until the snake leaves. The snake's behavior serves as releasing stimuli for toad defensive responses. Hayes (1989) described toad-snake interactions: "when the snake was active, close to the toad and facing it, the toad usually remained immobile; when the snake faced the opposite direction or remained still, the toad often hopped away" (p. 1012). Toads are also similar to frogs in their response to direct contact by a snake. If touched by the snake's body, toads tend to remain immobile, but they hop away if touched by the snake's head (Hayes, 1989), presumably because the toad is thereby chemically identified to the snake by tongue flicks. Hayes experimentally demonstrated that the strategy most often adopted by toads when a snake is nearby-that is, to remain immobile and to attempt to flee only when detectedis in fact favored by enhanced survival; toads that move before detection or remain immobile after detection are less likely to survive.

Freezing is not the only postural defense used by toads. Appleby (1971) described and illustrated the defensive postures of the common toad in response to an approaching grass snake (Natrix natrix helvetica). The toad inflates its body with air, stands on tiptoe with its body clear of the ground, and angles its body down toward the snake, thus presenting the largest area of its body to the snake (see also Bragg, 1945; Ewert \& Traud, 1979; Marchisin \& Anderson, 1978). A comparison of snake avoidance between anurans of Bufonidae and Ranidae families (Marchisin \& Anderson, 1978) suggested that toads present a more active defense against snakes than do frogs. Whereas frogs have a greater tendency to freeze, crouch, and hide, body inflation is a prominent defensive behavior of toads. Toads are also somewhat more likely to walk away from the snake. These differences are consistent with the fact that active avoidance conditioning with an electric shock US has been somewhat more successful in toads than in frogs (Boice, 1970; Crawford \& Langdon, 1966; Greding, 1971; Martof, 1962). The releaser-induced learning model would expect that instrumental conditioning of bufonid toads with an aversive stimulus could easily produce defensive stances instead of arbitrarily designated escape and avoidance responses.
The antipredator behavior of caudate amphibians is considerably more complex than that of frogs and toads, largely because salamanders have more antipredator defenses available than do most anurans. Major techniques employed by salamanders of various species include secretion of noxious materials, particularly by the tail, tail thrashing and autotomy (shedding), protean flipping and running, freezing, and defensive posturing that may involve aposematic display of brightly colored ventral surfaces. As is the case for anurans, SSDRs of salamanders vary widely, depending on ontogenetic state (Brodie, 1977), on population (Dowdey \& Brodie, 1989; Ducey \& Brodie, 1983) as well as species, on the nature of the encounter, and on the nature and behavior of the predator (Brodie, 1977; Brodie, Johnson, \& Dodd, 1974; Dodd \& Brodie, 1976; Ducey \& Brodie, 1983).

Salamanders of a species (Eurycea bislineata) subject to garter snake ( $T$. sirtalis) predation display different SSDRs to snake touch or tongue flicks that are quite similar to the differences described by Hayes (1989) for toads. Ducey and Brodie (1983; see also Dowdey \& Brodie, 1989) observed that most Eurycea ran when tongue flicked by a snake, and these usually escaped. None of the few that remained immobile survived. In contrast, all salamanders that remained immobile when touched by the body of the snake escaped the encounter, whereas only a third of those that ran survived.

Given the complexity of salamander SSDRs, it is perhaps not surprising that very few studies have been reported in which conditioning of an arbitrary response by use of electric shock was attempted. Two of three such articles available involved simple escape and passive avoidance learning (Hershkowitz, Segal, \& Samuel, 1972; Segal, Hershkowitz, Samuel, \& Bitterman, 1971; see also Moore \& Welch, 1940). In escape and active avoidance training, freezing interferes with learning, but freezing can increase apparent passive avoidance responding, since an animal that remains immobile after shock cessation avoids further shock. Passive avoidance may occur for any combination of three possible underlying reasons. First, freezing may simply be an unlearned SSDR; second, as Segal et al. (1971) noted, passive avoidance may result from classical conditioning of the stimulus cues associated with shock; or third, the immobile animal may in fact be actively withholding the punished response. Only the latter reason merits interpretation as instrumental conditioning.

In a third shock conditioning study (Schneider, 1968), larval Ambystoma punctatum were used in an active avoidance procedure very similar to that of Hoyer (1973) and Hoyer et al. (1971). This procedure, as previously noted, will produce apparent active avoidance conditioning if the shock-elicited SSDR consists of flight rather than freezing. This appears to be the case for Schneider's (1968) experiment, in which latencies for escape from shock were under 1 sec.

In other investigations of avoidance conditioning, bright light has been used in place of electric shock under the assumption that the bright light acts as an aversive rein- 
forcer for instrumental conditioning of tiger salamanders (Ambystoma tigrinum). Evidence consistent with that assumption is Ray's (1970) demonstration of successful oneway active avoidance conditioning to light. Other consistent evidence includes the conditioned active withdrawal responses of tiger salamanders from olfactory stimuli that have been paired with an intense light (Mason, Meredith, \& Stevens, 1981; Mason \& Morton, 1982; Mason \& Stevens, 1981; Mason, Stevens, $\&$ Rabin, 1980). This finding uncovers an interesting contradiction: in the laboratory, salamanders readily escape and avoid bright light; in the field, they posture and freeze in response to it. Terrestrial salamanders are typically found in dark places; beneath ground litter, rocks, and logs. A salamander is likely to be suddenly exposed to bright light only if uncovered by a foraging predator. One such predator (Brodie, 1977) noted that salamanders usually "exhibited immobility and antipredator postures when uncovered" (p. 523). Clearly, elucidation of the nature and extent of the involvement of learning in the antipredator behavior of salamanders has just begun. The diversity of antipredator defenses among the caudata should yield illuminating comparisons relevant to the issue of whether the mechanism underlying the learning of antipredator responses is arbitrary response conditioning or transfer of stimulus control over SSDRs.

The issues involved in learning among the reptilia are much the same as those concerning amphibians. Initial efforts to condition lizards to avoid an electric shock were quite unsuccessful. Powell (1967) used a two-way shuttle task with anoles (Anolis carolinensis) and found a $48 \%$ asymptote for escape responses and essentially no avoidance responses at all. A second similar study (Powell, 1968) with Anolis sagrei yielded a high level of escape responses (90\% or so) but again no avoidance. Switching to a one-way task obtained even poorer escape and avoidance from $A$. sagrei (Powell \& Mantor, 1969) and few avoidance responses from skinks (Eumeces inexpectatus, Powell \& Peck, 1970). Powell and Mantor (1969) attributed the failures to condition avoidance responses to the use of auditory and visual CSs that are ineffective for reptiles and to a "phyletic difference in learning ability" (p. 627).

Bicknell and Richardson (1973) obtained results generally comparable to those of Powell and associates (Powell, 1967, 1968; Powell \& Mantor, 1969) in the first phase of training collared lizards $(C$. collaris) and desert iguanas (Dipsosaurus dorsalis) in a one-way avoidance task. Escape latencies were again very brief, but initial levels of avoidance were unusually high (20-30\%) and then contrarily declined with additional training. In a second phase of training, Bicknell and Richardson (1973) modified the goalbox by inserting an opaque top and reducing the entrance from the full width of the box to a $5 \times 5 \mathrm{~cm}$ opening to give the effect of a dark tunnel. This change constituted only one of the more prominent of the many differences between this study and those of Powell and associates (Powell, 1967, 1968; Powell \& Mantor, 1969;
Powell \& Peck, 1970), who used transparent (glass, clear Lucite) experimental chambers. In any case, the collared lizards from Phase 1 immediately responded with $84 \%$ avoidances, whereas desert iguanas increased performance moderately to about $20 \%$ avoidances. Bicknell and Richardson attributed the differences in avoidance to differences in habitat: "It may be that the tunnel represents a more 'natural' escape route for collared lizards, which live among rocks and crevices but not for the desert iguanas which live among sand and bushes"' (p. 1062).

In a subsequent study, Richardson and Julian (1974) used only desert iguanas; the apparatus and procedure were similar to those in Phase 2 of Bicknell and Richardson's (1973) study. The outcome consisted of monotonically increasing avoidance that appeared to be approaching an asymptote near $100 \%$. The results were again attributed to habitat: "The desert iguana used in the present study typically escape into burrows" (Richardson \& Julian, 1974, p. 39). The releaser-induced model concurs fully with Richardson and Julian's final speculation "that the dark pseudo-tunnel ... acted as a releaser for the familiar natural burrow escape response"' (p. 39).

The possibility that freezing behavior can account for poor acquisition of active avoidance responses to electric shock, so frequently cited in the interpretation of amphibian conditioning studies, has found no comparable consideration as a solution for comparable problems in lizard learning. One reason certainly is that the consistently short escape latencies of lizards are incompatible with freezing, which generally appears to be a much less important SSDR for lizards than it is for many amphibians.

Schall and Pianka (1980) found little evidence of freezing in a field study of predator escape behaviors by whiptail lizards (Cnemidophorus spp.). These desert lizards are diurnal, rapidly moving, and widely foraging insectivores that are preyed upon by many birds, mammals, snakes, and other lizards. Five closely related species of whiptails that inhabit similar terrain nevertheless display a diversity of SSDRs, most of which are based on initial flight responses. Initial freezing is not a high-probability response for lizards of any whiptail species, not even one species ( $C$. exsanguis) with very cryptic dorsal patterns that make them extremely difficult to see when they are motionless. These lizards nevertheless first make short runs before freezing (Schall \& Pianka, 1980).

Apparently, the SSDRs of whiptails primarily involve active escape to a protective location rather than freezing. The releaser-induced learning model predicts that instrumental and classical responses conditioned with an electric shock should be similar in form to the SSDRs of lizards and quite unlike the responses of most amphibians. Some evidence on the issue was provided by Benes (1969), who trained whiptail lizards (C. tigris) in a discriminated avoidance task in which mealworms (Tenebrio molitor) were presented in the center of a 23-mm-diameter red or green colored disk. Feeding on the mealworm from the disk of one color had no adverse consequences for the lizard, whereas seizure of a mealworm from the other 
colored disk resulted in delivery of an aversive shock to the lizard's mouth.

The response to the shock alone, according to Benes (1969), was a hasty retreat, whereas, after training, responses to the shock disk varied considerably. The response of some lizards to presentation of the shock disk consisted of "violent hyperactivity with rapid running back and forth in the cage, jumping, and collisions with the cage walls"' (p. 717). This behavior was attributed by Benes to cage-produced restrictions on flight behavior, noting that "the only real escape from the shock disc was to turn away until it was removed. Many [lizards] did just that"' (p. 717). Other descriptions by Benes also suggest that the shock disk acquired control over active SSDRs of whiptails: "The lizards would often approach a shock disc, deliberately examine it, or just walk by and turn their heads in the direction of the disc, or frantically run past it"' (p. 717).

The diversity of reactions to the shock disk is consistent with the diversity of escape behaviors observed by Schall and Pianka (1980) among whiptails of any given species. Another interesting possibility is that the "hyperactivity" noted by Benes (1969) may well act as a social stimulus that releases an apparent alarm reaction among lizards, as has been described by Schall and Pianka (1980):

"Very often a $C$. tigris darting into a shrub would flush out one to six other whiptails which would in turn begin darting from shrub to shrub. A single lizard's sighting a human could result in an entire area being devoid of whiptails within a few seconds"' (p. 562; see also Gregory, 1979, p. 178).

Defensive behavior elicited by electric shock has remained largely uninvestigated in snakes and crocodilians, with a few such studies on turtles. In the lone study done with a one-way shuttle task (Ellis \& Spigel, 1966), turtles (Chrysemys picta marginata) showed no evidence of acquiring responses to avoid shock (anomalously, a group injected with cortisone did avoid). However, rapid passive avoidance was produced by shocking turtles when they attempted to climb the walls of an enclosure (Ellis \& Spigel, 1966; Spigel \& Ellis, 1965).

Granda, Matsumiya, and Stirling (1965) instrumentally conditioned an active avoidance head-withdrawal response in turtles (Pseudemys scripta elegans). Despite many differences in details, the experiment of Farris and Breuning (1977) provided a comparable classical conditioning study. In both investigations, a CS was followed by a US that produced head withdrawal. The US was presented on every trial by Farris and Breuning, but Granda et al. (1965) contingently omitted the US if a head-withdrawal response to the CS occurred before US presentation. Both procedures yielded high levels of CRs-head withdrawals in both cases.

\section{RECOGNITION OF NOXIOUS AND PALATABLE FOOD}

Food recognition involves discrimination between edible and inedible food-like objects, and two different manifestations of the releaser-induced learning mechanism are involved. Acquisition of food recognition begins when an animal encounters a novel object that releases initial feeding behaviors. If feeding responses result in aversive effects such as foul flavors, pain, and gastric distress, the animal may cease to feed, expelling the object instead. The animal may, as a result of this experience, subsequently avoid and withdraw from the noxious stimulus and may even display behaviors similar to antipredator defensive responses. The same food-like object that initially released approach and contact comes to release avoidance and defensive behavior.

\section{Learned Recognition of Unpalatable Food}

Acquired recognition of unpalatable food has been widely reported for amphibians and reptiles. Cott (1936) placed common toads at the entrance of a honeybee (Apis millifera) hive and observed that the toads not only gradually ceased snapping at the bees but also showed active escape behavior when placed at the hive entrance. A better controlled study was conducted by Brower, Van Zandt Brower, and Westcott (1960) in the context of investigations of aggressive mimicry. Experimental southern toads, B. terrestris, were offered an edible insect (the blue pirate dragonfly, Chydiplax longipennis), stinging bumblebees, Bombus americanotum, and the edible asilid fly, Mallophora bomboides, mimic of the bumblebee. Control toads were offered only dragonflies and the asilid mimic, which they largely continued to attack and eat over the course of the study. Experimental toads attacked the first bumblebee offered, but after accepting a second, they subsequently took bumblebees and mimics only very occasionally while continuing to eat dragonflies. Live bumblebees with the sting removed were eaten by the control toads in a later test. Particularly fascinating, however, is the report by Brower et al. (1960) that the experimental toads often adopted their distinctive defensive posture (described by Appleby, 1971; Bragg, 1945; Ewert \& Traud, 1979; Hayes, 1989; Laming \& Austin, 1981; Marchisin \& Anderson, 1978; Woodruff, 1977) when offered a bumblebee. This suggests after experiencing a bee sting while feeding, a toad releases defensive behavior to initially neutral stimulus features of bees.

Similar results were reported by Van Zandt Brower and Brower (1962; see also Brower \& Van Zandt Brower, 1962). Some 67 wild-caught southern toads were screened with presentations of two mealworms, $T$. molitor, and two droneflies, Eristalis vinetorum, mimics of the honeybee. The $\mathbf{4 4}$ toads that ate all four test insects and all subsequent mealworms were divided into two equal groups and given five pairs of honeybee and mealworm presentations followed by a dronefly test. The two groups differed in that the experimental toads were given live, intact honeybees, whereas the control toads received dead honeybees with the sting removed. Significantly fewer of the experimental toads ate the final test dronefly than did the controls. Of the 22 experimental toads, 13 displayed the defensive posture to a honeybee or the mimic after eating one or more live bees, whereas only 3 controls were observed to show defensive responses to bee or mimic. 
In addition, Eibl-Eibesfeldt (1951; cited by Brzoska \& Schneider, 1978) reported that common toads showed avoidance and withdrawal responses to inedible dummy prey after several fruitless attacks, and Brzoska and Schneider (1978) also mentioned observing defensive responses by common toads after they had accepted several unpalatable prey.

Other investigators have reported apparently learned avoidance of distasteful insects. In the green anole (Anolis carolinensis, Sexton, Hoger, \& Ortleb, 1966), and ameiva (Ameiva ameiva, Boyden, 1976) lizards, apparently the avoidance is based on the visual appearance of the insects. Boyden (1976) found that when visual characteristics (wing color or pattern) of unpalatable aposematic butterflies were removed or obliterated, attacks by preyexperienced ameiva were reinstated. Sternthal (1974) showed that leopard frogs could learn to discriminate between palatable and unpalatable food that differed in either visual or olfactory cues (see also Schaeffer, 1911). Four of 13 common toads were successfully trained by Brzoska and Schneider (1978) to avoid flies, Musca domestica, rendered unpalatable with lemon juice and quinine when presentation of the fly was accompanied by an intermittent tone. Mikulka, Hughes, and Aggerup (1980) successfully trained southern toads to discriminate between visually distinctive (natural and blue-dyed) palatable and unpalatable (HC1-dipped) meatballs. Again, active avoidance and defensive behavior were displayed in response to the sight of the aversive stimulus. Mikulka et al. reported that the "animals backed away from the bait, lowered their heads, and flattened themselves against the chamber floor"' (p. 56). In a second experiment, Mikulka et al. managed to train toads to discriminate HC1-dipped mealworms from palatable ones on the basis of habitat cues (white vs. black feeding chamber).

Boycott and Guillery (1962) shocked turtles (Pseudemys scripta elegans) for feeding responses to food presented with an odorant CS but did not shock feeding responses to food presented without the odorant. Thus, at the beginning of training, feeding responses were predictors of shock. The effect of the shock was "to produce retraction of the head and to deter the animal from feeding" (p. 569). During the early stages of training, after the turtles had received a few shocks, many displayed defensive responses to the food. They cautiously approached the food with head retracted and did not feed. Apparently the ability to induce defensive responses from the turtles, responses initially elicited only by the shock, was transferred to the food stimuli.

Sexton (1964) reported particularly interesting observations on wild-caught green anole lizards offered unpalatable aposematic (firefly, Photinus pyralus, and milkweed bug, Oncopeltus fasciatus), stinging (mutillid wasps, Dasymutilla occidentalis, Dasymutilla spp.), and palatable (mealworm) insects. The behavior of the anoles after they ceased to attack the aposematic and stinging insects is of primary interest. Some lizards gave dewlap extension displays, particularly to the mutillid wasps but also to the distasteful insects. A notable behavior of lizards offered aposematic insects consisted of biting responses to small, inanimate objects. These "displacement" responses are reminiscent of "off-key" responses of pigeons, Columba livia, subjected to an omission autoshaping procedure (see Hearst \& Jenkins, 1974, p. 22). In the omission procedure, pecks to the key when it was illuminated to predict food delivery had the negative effect of canceling the otherwise scheduled food presentation. After experience with the omission procedure, pigeons often avoid pecking at the key but instead peck at other stimulus features (e.g., a screwhead) near the key. Similar behavior by common toads was observed by Eibl-Eibesfeldt (1951; cited in Brzoska \& Schneider, 1978) and by Brzoska and Schneider (1978).

Learned recognition and avoidance of unpalatable food is understandable within the releaser-induced recognition model without resort to instrumental conditioning and reinforcement mechanisms. The releaser-induced model need merely note that aversive stimuli are releasers of rejection, avoidance, and defensive behaviors and that the direction of these behaviors is an integral part of the transferred releasing valence. Thus, animals display defensive behavior toward originally neutral stimuli after they have been associated with an aversive stimulus, and they also attempt to escape and move away from such assignedvalence stimuli.

\section{Conditioned Aversions}

Exposure of an animal to a novel foodstuff followed by the induction of gastric illness produces in the animal an aversion to the foodstuff. Formation of such conditioned aversions is largely restricted to the sensory features of the material consumed as opposed to any other predictive environmental stimuli. Since conditioned aversions are formed by the Pavlovian conditioning procedure, the failure of most stimuli to function as Pavlovian CSs for conditioned aversions is considered to constitute a severe constraint on the generality of the Pavlovian model (see, e.g., Hollis, 1982). Conditioned aversions have been examined in only one reptile, the garter snake, $T$. sirtalis (Burghardt, Wilcoxon, \& Czaplicki, 1973; Czaplicki, Porter, \& Wilcoxon, 1975), and one amphibian, the toad, $B$. americanus (Mikulka, Vaughan, \& Hughes, 1981), but there is little reason to doubt that ability to acquire conditioned aversions is widely distributed among amphibians and reptiles.

Another theoretically important feature of conditioned aversions is that, unlike in other forms of Pavlovian conditioning, a close temporal association between the CS (novel food) and the US (illness) is unnecessary to aversion formation. Burghardt et al. (1973) and Czaplicki et al. (1975) found evidence for learned aversions in garter snakes formed in one trial with a 30-min interval between the CS (feeding of earthworms, Lumbricus terresteris) and US (injection of $\mathrm{LiCl}$ ). The occurrence of long-delay conditioned aversions implies that a neural representation of the gustatory characteristics of the novel food substance is formed when the food is consumed and that represen- 
tation can be reinstated later to acquire releasing valence during the illness.

In releaser-induced recognition terms, gastric distress activates systems for rapidly clearing the gastrointestinal tract (e.g., nausea, vomiting) and reinstates memory for recently eaten novel food. If any reinstated memory is for a novel foodstuff, the sensory qualities of that novel substance acquire induced valence to release nausea and vomiting (see Hollis, 1982). Of particular interest is that the determinant of whether control is transferred is the degree of novelty of the foodstuff rather than the temporal relations between foodstuff and illness.

\section{Learned Recognition of Food}

Most amphibians and reptiles must find their own food from birth onward. Parental feeding of young is virtually nonexistent (however, see Salthe \& Mecham, 1974, and Weygoldt, 1980, for a few exceptions). Consequently, initial food recognition by amphibians and reptiles can be expected to occur rapidly, early in ontogeny, and as a result of endogenous processes. Learning is more likely to be involved in expansion and modification of initial food selections. Responsiveness of newborn animals to stimulus cues from potential prey has been evaluated for a number of snake and lizard species. As expected, ingestively naive snakes selectively directed feeding behaviors to prey stimuli at their initial presentation (Genus Thamnophis: Arnold, 1977, 1981; Burghardt, 1966, 1967a, 1969, 1970, 1971, 1975; Burghardt \& Hess, 1968; Dix, 1968; Genus Natrix: Burghardt, 1968; Dix, 1968; Dunbar, 1979; Gove \& Burghardt, 1975; Genus Elaphe: Burghardt \& Abeshaheen, 1971; Morris \& Loop, 1969; Genus Narodia: Mushinsky \& Lotz, 1980; Genus Naja: Stimac, Radcliffe, \& Chiszar, 1982; Genus Opheodrys and Storeria: Burghardt, 1967a), and so did lizards (Genus Eumeces: Burghardt, 1973; Loop \& Scoville, 1972; Genus Sceloporus: Reznick, Sexton, \& Mantis, 1981). In general, unlearned preferences for particular prey stimuli correspond to prey preferences of adults of the species or, indeed, of just the population (Arnold, 1977, 1981; Burghardt, 1970; Dix, 1968) under examination.

Visual features of prey, in particular prey movement, are widely assumed to be virtually universal unlearned releasers of food-seeking behaviors in insectivorous frogs and toads (e.g., see Brzoska \& Schneider, 1978; Ingle, 1968; Sternthal, 1974) and lizards (Askew, Musimeci, Sloane, \& Stephan, 1970; Burghardt, 1964). For many snakes and some lizards, prey are initially identified by means of chemosensory information provided to Jacobson's organ when the predator tongue flicks a potential prey (Wilde, 1938). For naive garter snakes, tongue contact appears to be essential to the release of prey attack, since at least one tongue flick always precedes prey attack (Sheffield, Law, \& Burghardt, 1968) and surgical removal of the tongue of unfed newborn garter snakes has completely eliminated feeding responses to prey (Burghardt \& Pruitt, 1975).

Sheffield et al. (1968) reached two interesting conclusions. One is that tongue contact before prey attack may not be feasible with alert and quick-moving prey such as frogs (cf. Burghardt, 1969). However, as previously noted (Gregory, 1979; Licht, 1986), some snakes do not appear to be capable of visually locating immobile prey (see Burghardt, 1966; Burghardt \& Hess, 1968; Burghardt \& Pruitt, 1975; Herzog \& Burghardt, 1974). This "perceptual blindness" of the predator makes freezing an effective defense against nearby snakes, a defense that is employed by frogs and also toads and salamanders. The second noteworthy conclusion of Sheffield et al. (1968) is "that conditioning might occur during ontogeny to allow 'stimulus substitution' of the classical type" (p. 12).

The evidence of extensive predispositions of newborn animals to respond selectively to prey in the absence of any significant prior experience with that prey contrasts with equally extensive evidence that feeding experience with prey can modify food choice. Effects of primacy of various degrees of strength and permanence have been shown on food preferences of a number of turtlesdiamond-back terrapins, Malaclemys hybrids (Allen \& Littleford, 1955), red-eared turtles (Mahmoud \& Lavenda, 1969), snapping turtles, Chelydra serpentina (Burghardt, 1967b; Burghardt \& Hess, 1966), and loggerhead sea turtles, Caretta caretta (Grassman \& Owens, 1982)-and also snakes: common garter snake, $T$. sirnalis (Arnold, 1978; Fuchs \& Burghardt, 1971), rat snake, Elaphe obsoleta hybrids (Loop, 1970), and red spitting cobra (Stimac et al., 1982).

Early learning effects in food selection have often been interpreted in terms of an imprinting model that emphasizes primacy and permanence in the development of food preferences (Hess, 1964). These emphases developed from a longstanding and widespread view of imprinting as a recognition process separate from Pavlovian and instrumental conditioning. Irreversible food preferences based on exposure to the food during a "sensitive" period constitute the defining criteria for food imprinting. From the present viewpoint, food imprinting is just another set of phylogenetically adapted manifestations of the releaserinduced recognition mechanism.

Certainly the evidence for early learning of food recognition and preferences does not compel the concept of food imprinting. After all, if food recognition is not endogenous, animals that fail to learn to recognize food quickly cannot survive very long. Although food choices learned early may often be stronger than those learned later, such choices are not typically irreversible (Fuchs \& Burghardt, 1971), and their production is not restricted to a "sensitive period" (see, e.g., Mushinsky \& Lotz, 1980).

The imprinting model proposed simple exposure to a unitary stimulus as the mechanism for learning responses to that stimulus. However, more than simple exposure seems to be involved in the acquisition of food recognition and development of feeding behaviors. Rather, the usual pattern is that reptiles and amphibians are born with stimulus predispositions that control the release of phylogenetically preorganized feeding responses (see Burghardt, 1966; Burghardt \& Abeshaheen, 1971; Fuchs \& Burghardt, 1971; Herzog \& Burghardt, 1974). 
Unlearned releasers may be general stimulus characteristics of environmental objects such as size and movement (Askew et al., 1970; Burghardt, 1964, 1969; Herzog \& Burghardt, 1974; Ingle, 1968). Unlearned releasers may also be, as has been widely demonstrated for snakes, specific stimulus characteristics such as chemosensory features of particular prey species. In either case, the released responses are autotaxic to the releasing stimulus, the prey, thus exposing the inexperienced animal to proximal stimuli of olfactory and perhaps taste cues and, for snakes and lizards, the chemosensory cues provided to Jacobson's organ by tongue flicks. In the absence of any intervening noxious events, transfer of control over released responses can occur in two different ways. In one, transfer of control is induced from co-occuring but initially unrecognized sensory features of prey. The other way consists of temporally retrograde transfer, with control over each successive step in the feeding process transferred backward to earlier stimuli in the sequence.

Arnold (1978) provided a good example of such transfer. Garter snakes, as previously noted, do not visually locate immobile prey, and Arnold's naive garter snakes mostly ignored dead fish (Gambusia affinis), although they readily ate live moving fish (presented on a dry substrate). After their initial experience with live fish, the garter snakes fed indiscriminately on live and dead fish. Arnold concluded that "apparently $T$. sirtalis associate chemosensory cues with prey movement during the first experience with live fish, and in subsequent encounters, chemoreception alone is sufficient to elicit attack" (p. 460). Fuchs and Burghardt (1971) noted similar transfer. Most garter snakes do not eat chopped beef but can be induced to do so if the beef is mixed with extract from a favored food (earthworm). Gradually reducing the amount of worm extract left the snakes with feeding responses to beef alone.

The imprinting model has been invoked to explain several effects of early feeding experience on the behavior of the European spotted salamander, Salamandra salamandra. Luthardt and Roth (1979) reported that salamanders selectively gave feeding responses to dummy prey moved in accordance with the movement patterns of the prey provided to them as food during the first month after metamorphosis (see also Luthardt-Laimer, 1983). A second phenomenon resulting from feeding experience was subsequently examined. Salamanders raised with stationary prey for the 1st postmetamorphic month learn to find and attack motionless prey on the basis of olfactory cues (Luthardt \& Roth, 1983; Roth \& Luthardt, 1980). However, salamanders first exposed to dead prey at 1 , 3, or 6 months after metamorphosis do not learn to attack immobile prey (Luthardt-Laimer \& Roth, 1983).

An interesting feature of salamander hunting behavior is that in darkness, locating and attacking prey are based on odor cues alone, so salamanders accept stationary prey regardless of prior experience. In the light, however, attack is inhibited unless the insect moves or the salamander has had early experience with stationary prey. After locating a prey by odor, salamanders "often remained in front of it intensively sniffing and searching and even touching the prey with the snout without snapping at it" (Luthardt \& Roth, 1983, p. 76). Food recognition learning in the salamander provides an example of failure of CS-US contiguity to yield Pavlovian conditioning. The temporal relationship of prey odor with prey attack and consumption in the dark apparently did not suffice to yield general conditioning of prey attack to odor cues, since no conditioning effects were found in the light.

Acquisition of food recognition by salamanders has been investigated only infrequently. Hershkowitz and Samuel (1973) trained crested newts (Triturus cristatus) to discriminate between two prey-like stimuli. Two small (12mm-diameter) black stimuli were presented against a white background on the outside of a glass wall of the newts' home tank. One of the two stimuli was designated $S+$ and feeding snaps to it were followed by food presentation, whereas snaps to the other stimulus, $S-$, were not. The frequency of feeding snaps that were directed to $S+$ gradually increased to about $90 \%$. Interpretation of these findings as the result of instrumental conditioning of the feeding response seems quite straightforward, but it would be interesting to compare these results with the outcome of applying the autoshaping procedure.

\section{Search Image}

Evidence for the involvement of learning in food acquisition has sometimes been interpreted as the result of search image formation. The idea of a "search image" as a learned neural template for the sensory features of preferred food was originally suggested in a 1934 paper by Von Uexküll (printed in translation: Von Uexküll, 1957). A search image is formed by initial consummatory experience with palatable food. In informal observations that seem to have been neither replicated nor contradicted, Von Uexküll (1957) reported that a hungry toad given an earthworm would subsequently attack earthwormlike objects (e.g., a household match), whereas if given a spider it would snap at spider-like bits of moss or ants. Neither the species nor prior experience was specified for this, perhaps legendary, toad.

A concept similar to search image, termed strikeinduced chemosensory searching (SICS), has been proposed to account for the behavior of venomous snakes following striking and envenomation of a prey (Chiszar et al., 1983; O'Connell, Chiszar, \& Smith, 1981, 1983). Rattlesnakes, Crotalus v. viridis, and cobras, Naja naja kaoutia, $N$. mossambica pallida, display a sustained high rate of tongue flicking after striking prey. Presumably, the strike activates "a neural representation of an envenomated mouse which 'informs' the predator's searching behavior, that is, the snake ... continues to search until it detects extroceptive stimulation which matches this representation"' (O'Connell et al., 1981, pp. 343-344; see also Fuchs \& Burghardt, 1971, p. 278).

Recently, Melcer and Chiszar (1989a, 1989b) have clearly demonstrated that snakes learn to recognize a particular prey animal by the specific prey odors present dur- 
ing the envenomating strike. Odors present during the strike (but not those present earlier or later) acquire ability to release prey trailing behavior. The mechanism involved in SICS (and search image formation generally) differs in only one substantive way from the releaserinduced recognition mechanism as it has been discussed so far, and that is in the permanence of the induced control over behavior. Search images are clearly temporary, analogous to working memory (see, e.g., Honig, 1978). When predator or prey changes, a new search image is formed that replaces the previous one. Releaser-induced recognition is in no way contradictory to this conceptualization. Temporary rather than permanent transfer of releasing valence is simply another phylogenetic adaptation of the ubiquitous transfer-of-control mechanism.

\section{CONSPECIFIC RECOGNITION}

Evidence for acquired recognition of conspecifics among reptiles and amphibians is definitely very sparse. Conspecific recognition seems to be largely innate, often appearing to depend on only a few stimulus or behavioral characteristics that release relevant intraspecific behavior (see, e.g., B. Greenberg \& Noble, 1944). Recognition may also be only crudely preprogrammed and then mediated by habitat selection and/or behavioral mechanisms. During the breeding season, for example, males of some toad species amplex (mating clasp) any moving objects of suitable size. Since this occurs at or near the breeding area, normally only a conspecific toad is amplexed, with a release call and movement that dissolves infertile unions immediately (see, e.g., Eibel-Eibesfeldt, 1975, pp. 84$85,188-189)$. Thus, evidence that older bullfrog females selectively mate with larger males (Howard, 1978) may occur because older males occupy superior territory. Apparent experience-dependent mate recognition may therefore in fact be mediated by territorial recognition. In any case, inference of learning from behavioral change resulting from nonspecific experience is hazardous at best.

Further evidence for learned conspecific recognition includes differential responses to neighbor and nonneighbor conspecifics by salamanders, Plethodon jordani (Madison, 1975) and some indication that experience affects sibling recognition in toad tadpoles: $B$. boreas (O'Hara \& Blaustein, 1982) and B. americanus (Waldman, 1981). The evidence, however, is neither direct nor compelling. In general, tadpoles of these toads and some frogs, $R$. cascadae (Blaustein \& O'Hara, 1981) and $R$. sylvatica (Cornell, Berven, \& Gamboa, 1989; Waldman, 1984), preferentially aggregate with siblings when either raised in sibling groups or raised isolated from conspecifics (Blaustein \& O'Hara, 1981, Waldman, 1981). However, some toad tadpoles raised in mixed groups of siblings and nonsiblings rapidly lose their preference for siblings (O'Hara \& Blaustein, 1982; Waldman, 1981). According to Waldman (1981), "a critical or sensitive period exists early in development during which tadpoles learn and/or acquire appropriate identifiable traits, and individuals form a rela- tively permanent recognition 'template' that they later use to recognize siblings" (p. 353). The process involved, Waldman (1981) suggested, consists of imprinting. Evidence for such a process remains scant (Blaustein \& O'Hara, 1982, 1986; Cornell et al., 1989; Waldman, 1986).

Social interactions among conspecifics constitute a potentially rich area for the development of the releaserinduced recognition mechanism, an area that remains largely unexamined. Conspecific recognition often results from genetically programmed interactions. An invariant species-specific feature (e.g., odor, call) is genetically coded to release conspecific-appropriate behavior (e.g., filial, sexual). At the same time, releasing valence is transferred to other (e.g., visual) features of the originating animal. Such features alone then suffice to elicit conspecificappropriate responses. Thus, releaser-induced recognition provides a mechanism whereby a genetically transmittable "known" mediates recognition of an environmentally variable "unknown" (cf. Lorenz, 1969, p. 48).

Ability to confer experientially acquired stimulus recognition onto conspecifics obviously has great potential for evolutionary advantage to the members of species that possess such ability. As previously discussed, cultural transmission of acquired stimulus recognition by means of the releaser-induced recognition mechanism is straightforward enough in principle. An experienced animal emits a species- and stimulus-specific behavioral response upon encountering a biologically relevant (e.g., food, a predator) stimulus. The behavior serves as a releasing stimulus for conspecifics, a stimulus that both releases relevant responses (e.g., eating, avoidance) from observing conspecifics but may also have a spatial, temporal, or dynamic directional allotoxic component that serves to designate and convey releasing valence to the relevant stimulus for a naive observer.

Having noted that releaser-induced recognition interactions are a prominent aspect of social behavior, one must also note that a substantial portion of amphibian and reptile species have, at best, impoverished social relationships (Auffenberg, 1977; Carpenter, 1977b). Mating and egg deposit may be the entire social repertoire of some. Nevertheless, the scope of social behaviors that have been reported is quite extensive and includes calls and displays involved in adult conspecific interactions as well as complex interactions involved in parental care. However, there is little evidence for involvement of learning processes even in the more sophisticated social encounters. Whether this absence of evidence reflects a comparable absence of learning processes or just a continuing neglect of such matters by researchers is presently unclear. Thus, the present review only briefly points out areas that promise to yield exciting and fascinating insights into the evolutionary development of simpler communication systems.

Communication by behavioral variation in signature display action patterns (pushups and head bobs) occurs fairly widely, in anoline (see, e.g., Sigmund, 1983; Williams \& Rand, 1977) and iguanid (see, e.g., Carpenter, 1977a) 
lizards, whereas communication by vocalizations is found only in gekkonid lizards (Frankenburg, 1982; Marcellini, 1977). These forms of communication have potential for transmitting substantial amounts of information, but so far the evidence indicates nothing more complex than reciprocal release of interactive behaviors such as territorial defense.

Adult anurans also use a number of species and contextspecific calls and displays (Kluge, 1981; Schmidt, 1966; Townsend, Stewart, \& Pough, 1984; Wells, 1977), but there is no evidence as yet that such calls are anything except simple releasers of conspecific behavior. Calls are an important feature of crocodilian parental care, which is well developed even if not closely studied (Cott, 1971; Garrick \& Lang, 1977; Magnusson, 1980; Pooley \& Gans, 1976). Again, no clear evidence of learning has been reported. Parental care in amphibians and reptiles is mostly absent, but occasionally very extensive and detailed parental behavior has been observed.

Evans (1959) photographed remarkably complex and extended parental care given by a lizard, the skink $E$. obsoletus, to eggs and hatchlings. Weygoldt (1980) described similar complexity of maternal care by a South American frog, Dendrobates pumilio. Brood care by the female includes egg attendance, transport of tadpoles on her back to water-filled bromeliad leaf axils, and regular feeding of tadpoles with unfertilized eggs. The female cares for up to five tadpoles at once, each in a separate axil in two different bromiliads. The female deposits infertile eggs only in axils containing her own tadpoles. Eggs are not deposited in empty axils, axils containing dead larvae, or axils containing tadpoles other than her own. Weygoldt's observations of selective recognition are hard to explain in terms of species-specific releasers without resort to learning by individual experience. Either the frog mother learns to recognize her own offspring (or their location) individually, or the offspring learn to recognize (and respond only to) their own mother.

\section{HABITAT RECOGNITION}

There is extensive, albeit largely indirect, evidence for acquired habitat recognition in amphibians and reptiles. Breeding (see, e.g., Wells, 1977) and hibernation aggregations, homing (see, e.g., Barthalmus \& Bellis, 1972; McVey, Zahary, Perry, \& MacDougal, 1981), and territorial defense (see, e.g., Wells, 1977) all indicate recognition of specific habitats. Particularly interesting are the reports that habitat preferences are acquired very early in frogs, $R$. aurora (Wiens, 1970), $R$. cascadae (Wiens, 1972), salamanders, Aneides aeneus, Desmognathus ochriophaeus (Mushinsky, 1976), and sea turtles, Lepidochelys kempi (Grassman, Owens, McVey, \& Marquez, 1984). Again, imprinting has been the preferred descriptive model (see, e.g., Grassman et al., 1984; Immelmann, 1975; Mushinsky, 1976). Explanation of habitat recognition in terms of releaser-induced recognition (or any other mechanism) would require more infor- mation about habitat recognition than is presently available. In principle, however, releasing stimuli could guide an inexperienced animal to a suitable habitat. Releasers occurring at a suitable site would activate territorial behavior and transfer releasing valence to site-specific stimuli (e.g., odors; see Barthalmus \& Bellis, 1972; Grassman et al., 1984) that would release homing, defensive, and other relevant behaviors.

\section{CULTURAL TRANSMISSION}

Three ways in which stimulus recognition may be transmitted from an experienced animal to an inexperienced conspecific have been proposed: social facilitation, local enhancement, and imitation (Thorpe, 1963). Social facilitation refers to releasing-stimulus-released-response interactions among conspecifics, wherein the releasing stimulus is the behavior of one animal and the released response is the same behavior in an observing conspecific.

Social facilitation occurs extensively among vertebrates, beginning at birth. Hatching crocodilians call in response to disturbances at the nest, and the calls release nest excavation behavior by the mother (see, e.g., Cott, 1971; Garrick \& Lang, 1977). Calling is socially facilitated. If one hatchling calls, the others in the nest join (Cott, 1971). Hatchling green iguanas, Iguana iguana, emerge from nests and leave the nest area in groups (Burghardt, Green, \& Rand, 1977), strongly suggesting involvement of social facilitation in the organization of nest departure. Other examples are too numerous to mention, but they include synchronization of calling in frog mating choruses (e.g., those of $H$. regilla, Whitney \& Krebs, 1975; Wells, 1977), chorus shutdown to predators (Tuttle, Taft, \& Ryan, 1982), aggression in territorial males (e.g., $H$. rosenbergi, Kluge, 1981), and various aggregations of anurans (e.g., B. americanus, Beiswenger, 1975; X. laevis, Wassersug \& Hessler, 1971), newts (Notophthalmus viridescens, Pitkin \& Tilley, 1982), and garter snakes (Heller \& Halpern, 1982).

Social facilitation is not a recognition learning mechanism, since socially facilitated experience by itself does not usually lead to permanent change in behavior. In fact, social facilitation is not different in principle from other releasing-stimulus-released-response interactions between conspecifics, most of which involve releasing stimuli and released responses that are very different from each other. Local enhancement occurs when the behavior of an animal both releases the same behavior in a conspecific and directs that behavior to an environmental stimulus feature. N. Greenberg (1976) interpreted behavior of blue spiny lizards, Sceloporus cyanogenys, and green anoles as showing local enhancement when feeding by one lizard resulted in others' moving to the regular feeding area. Local enhancement, however, is usually inferred when both observer and demonstrator behaviors are directed to the same environmental feature-which doesn't seem to be the case here. In N. Greenberg's situation, presence of a feeding companion in the cage was no doubt a reli- 
able predictor of more food at the feeding site, and thus movement toward the feeding site may be interpreted as an effect of either reinforcement or autoshaping. Local enhancement may have occurred, however, as, for example, when the observer of a food-seeking lizard was described by $N$. Greenberg as moving "toward the site being approached by the first lizard" (p. 349). Other reports of local enhancement in reptiles or amphibians are difficult to find.

Imitation, as proposed by Thorpe (1963), requires that a novel or otherwise improbable act of one animal be actively copied by an observing companion. Considering the potential difficulty of determining when or whether "active copying"' has occurred, in the present discussion I will only consider the possibility that apparent imitation can result from social transmission of stimulus recognition by the releaser-induced recognition mechanism. The behavior of conspecifics is an important source of releasing stimuli for most animals. Many social releasers are also capable of effecting allotaxic transfer of releasing valence to other stimuli (see Suboski, 1989, 1990). As just one example, the sight of a conspecific eating is generally a powerful releaser of feeding behavior by the observer (see, e.g., N. Greenberg, 1976). If the food is unfamiliar, observation of the feeding behavior of one animal can serve to assign to the observer releasing valence for the material being consumed. Subsequently, just the stimulus features of that material are capable of releasing feeding behavior by the observer. The outcome is an apparent imitation of food preference.

N. Greenberg (1976) reported apparent cultural transmission of food recognition from a desert iguana, $D$. dorsalis, to its blue spiny lizard cagemates. Both species feed on insects, but only the desert iguana initially ate lettuce. When lettuce was the only food placed in the cage for a time, the blue spiny lizards oriented toward the feeding behavior of the desert iguana. According to Greenberg, " Their postures and motor patterns were remarkably like those of foraging lizards which had encountered nonmoving potential prey. Head-cocking and feeding intention movements were directed to both the lettuce on the ground and in the mouth of the Dipsosaurus"' (p. 349). Eventually 3 of the 4 blue spiny lizards had eaten lettuce and continued to eat lettuce after feeding of mealworms was resumed. Any inference that behavior change is based on observational experience is usually unwise and unwarranted in the absence of careful control conditions. Prudence suggests a conclusion restricted to the observation that the possibility of social learning processes in lizards is probably worth further investigation.

Aversive stimulus recognition by means of the releaserinduced recognition mechanism may also result from observation of the alarm and/or defensive behavior of another animal. Again, only a few reports even suggest the possibility of releaser-induced transfer of aversive stimulus recognition between reptilian or amphibian conspecifics. Boyden (1976), after observing the feeding behavior of lizards, suggested that "some Ameiva may learn to avoid unpalatable prey by observing other conspecifics" (p. 76), but Boyden gave no evidence.

Bustard (1968) offered an intriguing account of the behavior of approximately $\mathbf{4 0}$ juvenile crocodiles, Crocodylus porosus, in a small Papuan lake. All of the adults of the lake had been killed by hunters, and the juveniles were assumed to have hatched from eggs laid before the adults were slaughtered. The juveniles were spotlighted at night, approached by boat, and captured by hand if possible. On the first night, all the crocodiles permitted close approach, and 5 of 11 were captured and retained. On the second night, all again permitted close approach but dove quickly, and only 1 of 10 was captured. On a third excursion, 7 crocodiles of the 8 seen submerged when the boat was still a considerable distance away. Although by no means certain, it appears that at least some of the crocodiles engaged in evasive behavior in the absence of any prior direct experience with attempts at capture. Quite possibly, such crocodiles learned from observation of their lakemates' experience. However, increased wariness from the continued intrusions is another possible interpretation.

\section{RELEASER-INDUCED RECOGNITION: CRITERIA FOR IDENTIFICATION}

Three elements are involved in releaser-induced recognition learning: (1) a releasing-valence assigning stimulus, (2) a releasing-valence receiving stimulus, and (3) a relationship that effects transfer of releasing valence. In order to make a proper inference of the operation of releaser-induced recognition, each element must be isolated and identified. Mere occurrence of a releasing stimulus does not imply operation of the releaser-induced recognition mechanism. Any given releasing stimulus does not necessarily induce a transfer of control and thus may not enter into the releaser-induced recognition mechanism at all. Other releasing stimuli may only enter into temporally based (Pavlovian conditioning) transfer of releasing valence.

Unfortunately, operation of the releaser-induced mechanism is often early, sudden, subtle, and unnoticed. Much important learning, such as food and parent recognition, may occur considerably earlier in ontogeny than is expected. Valence-assigning releasing stimuli may be unobtrusive, particularly to a human observer. The occurrence of releasing-valence transfer requires the presence of a stimulus appropriate to the reception of releasing valence and actual transfer of releasing valence may require a complex configural, temporal, and/or dynamic relationship between the stimuli. In addition, releaser-induced recognition may only occur when the animal is in a particular developmental or physiological state. Finally, demonstration that releasing-valence transfer has occurred may well require the availability of appropriate supporting environmental stimuli. Certainly any preconceived expectation that releasing-valence transfer can be effected only by Pavlovian conditioning - that is, by a temporally predictive relationship between an arbitrarily chosen neu- 
tral stimulus and a releasing stimulus-will surely fail to identify many important forms of recognition learning.

\section{REFERENCES}

Allen, J. F., \& Litrleford, R. A. (1955). Observations on the feeding habits and growth of immature diamondback terrapins. Herpetologica, 11, 77-80.

Altig, R., \& Christensen, M. T. (1981). Behavioral characteristics of the tadpoles of Rana hecksheri. Journal of Herpetology, 15, 151-154.

APPLEBY, L. G. (1971). British snakes. London: John Baker.

ARNOLD, S. (1977). Polymorphism and geographic variation in the feeding behavior of the garter snake, Thamnophis elegans. Science, 197, 676-678.

ARNOLD, S. J. (1978). Some effects of early experience on feeding responses in the common garter snake, Thamnophis sirtalis. Animal Behaviour, 26, 455-462.

ARNOLD, S. J. (1981). Behavioral variation in natural populations. II. The inheritance of a feeding response in crosses between geographic races of the garter snake, Thamnophis elegans. Evolution, 35, 510-515.

Askew, H. R., Musimeci, M., SlonNe, L., \& Stephan, L. (1970). Effects of prey movement and background on predatory behavior of chameleons. Psychonomic Science, 20, 171.

AUFFENBERG, W. (1977). Display behavior in tortoises. American Zoologist, 17, 241-250.

Barthalmus, G. T., Bellis, E. D. (1972). Home range, homing and the homing mechanism of the salamander, Desmognathus fuscus. Copeia, 632-642.

BEISWENGER, R. E. (1975). Structure and function in aggregations of tadpoles of the American toad, Bufo americanus. Herpetologica, 31 , 222-233.

BENES, E. S. (1969). Behavioral evidence for color discrimination by the whiptail lizard, Cnemidophorus tigris. Copeia, 707-722.

Bicknell, A. T., \& Richardson, A. M. (1973). Comparison of avoidance learning in two species of lizards, Crotaphytus collaris and Dipsosaurus dorsalis. Psychological Reports, 32, 1055-1065.

Biederman, G. B., D'Amato, M. R., \& Keller, D. M. (1964). Facilitation of discriminated avoidance learning by dissociation of CS and manipulandum. Psychonomic Science, 1, 229-230.

Bitterman, M. E. (1964). An instrumental technique for the turtle. Joumal of the Experimental Analysis of Behavior, 7, 189-190.

Blaustein, A. R., \& O'HARA, R. K. (1981). Genetic control for sibling recognition? Nature, 290, 246-248.

Blaustein, A. R., O'Hara, R. K. (1982). Kin recognition cues in Rana cascadae tadpoles. Behavioral \& Neural Biology, 36, 77-87.

Blaustein, A. R., \& O'HaRA, R. K. (1986). Kin recognition in tadpoles. Scientific American, 254(1), 108-116.

BoICE, R. (1970). Avoidance learning in active and passive frogs and toads. Journal of Comparative \& Physiological Psychology, 70 154-156.

Boice, R., Qunnty, C. B., \& Williams, R. C. (1974). Competition and possible dominance in turtles, toads, and frogs. Journal of Comparative \& Physiological Psychology, 86, 1116-1131.

Bolles, R. C. (1970). Species-specific defense reactions and avoidance learning. Psychological Review, 77, 32-48.

Boycort, B. B., \& GUILLERY, R. W. (1962). Olfactory and visual learning in the red-eared terrapin, Pseudemys scripta elegans (Wied). Journal of Experimental Biology, 39, 567-577.

BOYDEN, T. C. (1976). Butterfly palatability and mimicry: Experiments with Ameiva lizards. Evolution, 30, 73-81.

BraGG, A. N. (1945). Notes on the psychology of frogs and toads. Journal of General Psychology, 32, 27-37.

BRANDT, R. (1947). Transmetamorphic memory in Ambystoma texanum. Herpetologica, 3, 171.

Brattstrom, B. H. (1974). The evolution of reptilian social behavior. American Zoologist, 14, 35-49.

Brodie, E. D., JR. (1977). Salamander antipredator postures. Copeia, 523-535.

BRodie, E. D., JR., \& FormanowiCz, D. R., JR. (1987). Antipredator mechanisms of larval anurans: Protection of palatable individuals. Herpetologica, 43, 369-373.

Brodie, E. D., JR., Johnson, J. A., \& DodD, C. K., JR. (1974). Immobility as a defensive behavior in salamanders. Herpetologica, $\mathbf{3 0}$, 79-85.

Brower, L. P., \& VAN ZaNDT Brower, J. (1962). Investigations into mimicry. Natural History, 71(4), 8-19.

Brower, L. P., VAN ZandT Brower, J., \& Westcott, P. W. (1960). Experimental studies of mimicry 5. The reactions of toads (Bufo terrestris) to bumblebees (Bombus americanortum) and their robberfly mimics (Mallophora bomboides), with a discussion of aggressive mimicry. American Naturalist, 94, 343-355.

BrzoskA, J., \& SCHNEIDER, H. (1978). Modification of prey-catching behavior by learning in the common toad (Bufo b. bufo [L], Anura, Amphibia): Changes in responses to visual objects and effects of auditory stimuli. Behavioural Processes, 3, 125-136.

BURGHARDT, G. [M.] (1964). Effects of prey size and movement on the feeding behavior of the lizards Anolis carolinensis and Eumeces fasciatus. Copeia, 576-578.

BURGHARDT, G. M. (1966). Stimulus control of the prey attack response in naive garter snakes. Psychonomic Science, 4, 37-38.

BuRgharDT, G. M. (1967a). Chemical-cue preference of inexperienced snakes: Comparative aspects. Science, 157, 718-721.

BuRghardT, G. M. (1967b). The primacy effect of the first feeding experience in the snapping turtle. Psychonomic Science, 7, 383-384.

Burghardt, G. M. (1968). Chemical preference studies on newborn snakes of three sympatric species of Natrix. Copeia, 732-737.

BurghardT, G. M. (1969). Comparative prey-attack studies in newborn snakes of the genus Thamnophis. Behaviour, 33, 77-114.

BURGHARDT, G. M. (1970). Intraspecific geographical variation in chemical food cue preferences of newborn garter snakes (Thamnophis sirtalis). Behaviour, 36, 246-257.

BuRghardT, G. M. (1971). Chemical-cue preferences of newborn snakes: Influence of prenatal maternal experience. Science, 171, 921-923.

BURGHARDT, G. M. (1973). Chemical release of prey attack: Extension to naive newly hatched lizards, Eumeces fasciatus. Copeia, 178-181.

BurghardT, G. M. (1975). Chemical prey preference polymorphism in newborn garter snakes Thamnophis sirtalis. Behaviour, 52, $202-225$.

BURGHARDT, G. M. (1977). Learning processes in reptiles. In A. C. Gans \& D. W. Tinkle (Eds.), Biology of the reptilia: Ecology and behavior (Vol. 7, pp. 555-681). New York: Academic Press.

Burghardt, G. M., \& ABEShaheEN, J. P. (1971). Responses to chemical stimuli in newly hatched snakes of the genus Elaphe. Animal Behaviour, 19, 486-489.

BurghardT, G. M., Green, H. W., \& RAND, A. S. (1977). Social behavior in hatchling green iguanas: Life at a reptile rookery. Science, 195, 689-691.

BurgharDt, G. M., \& Hess, E. H. (1966). Food imprinting in the snapping turtle, Chelydra serpentina. Science, 151, 108-109.

BurghardT, G. M., \& Hess, E. H. (1968). Factors influencing the chemical release of prey attacks in newborn snakes. Journal of Comparative \& Physiological Psychology, 66, 289-295.

Burghardt, G. M., \& Pruitt, C. H. (1975). Role of the tongue and senses in feeding of naive and experienced garter snakes. Physiology \& Behavior, 14, 185-194.

Burghardt, G. M., Wilcoxon, H. C., \& Czaplicki, J. A. (1973). Conditioning in garter snakes: Aversion to palatable prey induced by delayed illness. Animal Learning \& Behavior, 1, 317-320.

BusTARD, H. R. (1968). Rapid learning in wild crocodiles (Crocodylus porosus). Herpetologica, 24, 173-175.

CARPENTER, C. C. (1977a). The aggressive displays of three species of South American iguanid lizards of the genus Tropidurus. Herpetologica, 33, 285-289.

CARPENTER, C. C. (1977b). Communication and displays of snakes. American Zoologist, 17, 217-223.

CAsTeEL, D. B. (1911). The discriminative ability of the painted turtle. Journal of Animal Behavior, 1, 1-28.

Chiszar, D., Stimac, K., Poole, T., Miller, T., Radcliffe, C. W., \& SMITH, H. M. (1983). Strike induced chemosensory searching in cobras (Naja naja kaouthia, N. mossambica pallida). Zeitschrift für Tierpsychologie, 63, 51-62. 
Chu, P. K., MCCAIN, G. (1969). Discrimination learning and extinction in toads. Psychonomic Science, 14, 14-15.

Cornell, T. J., Berven, K. A., \& Gamboa, G. J. (1989). Kin recognition by tadpoles and froglets of the wood frog Rana sylvatica. Oecologia, 78, 312-316.

Cort, H. B. (1936). The effectiveness of protective adaptations in the hive-bee, illustrated by experiments on the feeding reactions, habit formation, and memory of the common toad (Bufo bufo bufo). In Proceedings of the Zoological Society of London (pp. 111-133). London: Zoological Society.

CotT, H. B. (1971). Parental care in the crocodilia, with special reference to Crocodylus niloticus. In Crocodiles: Proceedings of the First Working Meeting of Crocodile Specialists (Suppl: Paper No. 32, pp. 166-180). Morges, Switzerland: International Union for Conservation of Nature and Natural Resources.

Crawford, F. T., LANGDON, J. W. (1966). Escape and avoidance responding in the toad. Psychonomic Science, 6, 115-116.

Czaplicki, J. A., Porter, R. H., \& Wilcoxon, H. C. (1975). Olfactory mimicry involving garter snakes and artificial models and mimics. Behaviour, 54, 60-71.

Davidson, R. E., \& Richardson, A. M. (1970). Classical conditioning of skeletal and autonomic responses in the lizard (Crotaphytus collaris). Physiology \& Behavior, 5, 589-594.

DAvidson, R. S., JR. (1966). Laboratory maintenance and learning of Alligator mississipiensis. Psychological Reports, 19, 595-601.

De Rosa, C. T., \& TAYLOR, D. H. (1982). A comparison of compass orientation mechanisms in three turtles (Trionyx spinifer, Chrysemys picta and Terrapene carolina). Copeia, 394-399.

Dix, M. W. (1968). Snake food preference: Innate intraspecific geographic variation. Science, 159, 1478-1479.

DodD, C. K., JR., \& BRodIE, E. D., JR. (1976). Defensive mechanisms of neotropical salamanders with an experimental analysis of immobility and the effect of temperature on immobility. Herpetologica, 32 , 269-290.

Dole, J. W., Rose, B. B., \& TACHIKI, K. H. (1981). Western toads (Bufo boreas) learn odor of prey insects. Herpetologica, 37, 63-68.

DowDEY, T. G., \& BrodiE, E. D., JR. (1989). Antipredator strategies of salamanders: Individual and geographical variation in responses of Eurycea bislineata to snakes. Animal Behaviour, 38, 707-711.

DUCEY, P. K., \& BRODIE, E. D., JR. (1983). Salamanders respond selectively to contacts with snakes: Survival advantage of alternative antipredator strategies. Copeia, 1036-1041.

Dunbar, G. L. (1979). Effects of early feeding experience on chemical preference of the northern water snake Natrix s. sipedon (Reptilia, Serpentes, Colubridae). Journal of Herpetology, 13, 165-169.

EIBL-EiBesFELDT, I. (1951). Nahrungserwerb und Beuteschema der Erdkröte (Bufo bufo L.). Behaviour, 4, 1-35.

EIBL-EIBESFELDT, I. (1975). Ethology: The biology of behavior (2nd ed.). New York: Holt, Rinehart \& Winston.

Ellins, S. R., Cramer, R. E., \& Martin, G. C. (1982). Discrimination reversal learning in newts. Animal Learning \& Behavior, 10 , 301-304.

Ellis, K. R., \& Sigel, I. M. (1966). Effects of cortisone on active and passive avoidance acquisition in the turtle. Proceedings of the 74th Annual Convention of the American Psychological Association, 2, 115-116.

Evans, L. T. (1959). A motion picture study of maternal behavior of the lizard, Eumeces obsoletus, Baird and Gizard. Copeia, 103-110.

EWERT, J.-P. (1980). Neuroethology. An introduction to the neurophysiological fundamentals of behavior. New York: Springer-Verlag.

EwERT, J.-P., \& TraUd, R. (1979). Releasing stimuli for antipredator behaviour in the common toad (Bufo bufo) (L). Behaviour, 68, 170-180.

FARRIS, H. E., \& BreUNING, S. E. (1977). Post-conditioning habituation and classically conditioned head withdrawal in the red-eared turtle (Chrysemys scripta elegans). Psychological Record, 27, 307-313.

Ferguson, D. E., Landreth, H. F., \& McKeown, J. P. (1967). Sun compass orientation of the northern cricket frog, Acris crepitans. Animal Behaviour, 15, 45-53.
FLOWER, S. S. (1927). Loss of memory accompanying metamorphosis in amphibians. In Proceedings of the Zoological Society of London (pp. 155-156). London: Zoological Society.

FranKEnBerg, E. (1982). Vocal behavior of the Mediterranean house gecko, Hemidactylus turcicus. Copeia, 770-775.

Franzisket, L. (1963). Characteristics of instinctive behaviour and leaming in reflex activity of the frog. Animal Behaviour, 11, 318-324.

Fuchs, J. L., * BuRghard, G. M. (1971). Effects of early feeding experience on the responses of garter snakes to food chemicals. Leaming \& Morivation, 2, 271-279.

Gans, C., Parsons, T. S. (1966). On the origin of the jumping mechanism in frogs. Evolution, $20,92-99$.

GARRICK, L. D., LANG, J. W. (1977). Social signals and behaviors of adult alligators and crocodiles. American Zoologist, 17, 225-239.

Goldstein, A. C., Spies, G., Sepinwall, J. (1964). Conditioning of the nictitating membrane in the frog, Rana p. pipiens. Joumal of Comparative \& Physiological Psychology, 57, 456-458.

Gormezano, I., KenoE, E. J. (1975). Classical conditioning: Some methodological-conceptual issues. In W. K. Estes (Ed.), Handbook of learning and cognitive processes (Vol. 2, pp. 143-179). Hillsdale, NJ: Erlbaum.

Gove, D., \& BurghardT, G. M. (1975). Responses of ecologically dissimilar populations of the water snake Natrix $s$. sipedon to chemical cues from prey. Joumal of Chemical Ecology, 1, 35-40.

Granda, A. M., Matsumiya, Y., StiRling, C. E. (1965). A method for producing avoidance behavior in the turtle. Psychonomic Science, 2, 187-188.

Grassman, M. A., \& OWENS, D. W. (1982). Development and extinction of food preferences in the loggerhead sea turtle, Caretta caretta. Copeia, 965-969.

Grassman, M. A., Owens, D. W., McVey, J. P., \& Marquez, M. R. (1984). Olfactory-based orientation in artificially imprinted sea turtles. Science, 224, 83-84.

Greding, E. J., JR., (1971). Comparative rates of learning in frogs (Ranidae) and toads (Bufonidae). Caribbean Joumal of Science, 11, 203-208.

GREenBerG, B., Noble, G. K. (1944). Social behavior of the American chameleon (Anolis carolinensis Voigt). Physiological Zoology, 17, 392-439.

GREenBerg, N. (1976). Observations of social feeding in lizards. Herpetologica, 32, 348-352.

GREeNWALD, O. E. (1974). Thermal dependence of striking and prey capture by gopher snakes. Copeia, 141-148.

Gregory, P. T. (1979). Predator avoidance behavior of the red-legged frog (Rana aurora). Herpetologica, 35, 175-184.

HARVEY, C. B., Ellis, C., \$ TATE, M. (1976). Inhibition of the righting reflex in the common bullfrog (Rana catesbiana) employing an operant-avoidance procedure. Bulletin of the Psychonomic Society, 7, 57-58.

Hawkins, R. D., KANDEL, E. R. (1984). Is there a cell-biological alphabet for simple forms of learning? Psychological Review, 91, 375-391.

HAYES, F. E. (1989). Antipredator behavior of recently metamorphosed toads (Bufo a. americanus) during encounters with garter snakes (Thamnophis s. sirtalis). Copeia, 1011-1015.

Hearst, E., \& Jenkins, H. M. (1974). Sign-tracking: The stimulusreinforcer relation and directed action. Austin, TX: Psychonomic Society.

Heller, S. B., \& HALPERN, M. (1982). Laboratory observations of aggregative behavior of garter snakes, Thamnophis sirtalis. Journal of Comparative \& Physiological Psychology, 96, 967-983.

HershKowTIZ, M., SAMUEL, D. (1973). The retention of leaming during metamorphosis of the crested newt (Triturus cristatus). Animal Behaviour, 21, 83-85.

Hershkowitz, M., Segal, M., \& Samuel, D. (1972). The acquisition of dark avoidance by transplantation of the forebrain of trained newts (Pleurodeles waltl). Brain Research, 48, 366-369.

Herzog, H. A., JR., BurgharDt, G. M. (1974). Prey movement and predatory behavior of juvenile western yellow-bellied racers, Coluber constrictor mormon. Herpetologica, 30, 285-289. 
HeSs, E. H. (1964). Imprinting in birds. Science, 146, 1128-1139.

HEws, D. K. (1988). Alarm response in larval western toads, Bufo boreas: Release of larval chemicals by a natural predator and its effect on predator capture efficiency. Animal Behaviour, 36, 125-133.

Hews, D. K., \& BlausteIN, A. R. (1985). An investigation of the alarm response in Bufo boreas and Rana cascadae tadpoles. Behavioral \& Neural Biology, 42, 47-57.

Hodos, W., \& CAMPBell, C. B. G. (1969). Scala naturae: Why there is no theory in comparative psychology. Psychological Review, 76, 337-350.

HoLlus, K. L. (1982). Pavlovian conditioning of signal-centered action patterns and autonomic behavior: A biological analysis of function. $A d-$ vances in the Stucty of Behavior, 12, 1-64.

Holmes, P. A., BitTerman, M. E. (1966). Spatial and visual habit reversal in the turtle. Joumal of Comparative \& Physiological Psychology, 62, 328-331.

HoNIG, W. (1978). Studies of working memory in the pigeon. In S. H. Hulse, H. Fowler, \& W. K. Honig. (Eds.), Cognitive processes in animal behavior (pp. 211-248). Hillsdale, NJ: Erlbaum.

How ARD, R. D. (1978). The evolution of mating strategies in bullfrogs, Rana catesbeiana. Evolution, 32, 850-871.

HoYer, W. J. (1973). Discontinuous shock and discriminated-avoidance learning by tadpoles (Rana pipiens). Psychological Reports, 33, 143-146.

Hoyer, W. J., Shafer, J. N., Mauldin, J. E., \& Corbett, H. T. (1971). Discriminated avoidance and escape conditioning with the tadpole (Rana pipiens). Psychonomic Science, 24, 247-248.

HRBÁČEK, J. (1950). On the flight reaction of tadpoles of the common toad caused by chemical substances. Experientia, 6, 100-101.

Humphries, D. A., \& Driver, P. M. (1970). Protean defense by prey animals. Oecologia, 5, 285-302.

IMMELMANN, K. (1975). Ecological significance of imprinting and early learning. Annual Review of Ecology \& Systematics, 6, 15-37.

INGLE, D. (1968). Visual releasers of prey-catching behavior in frogs and toads. Brain, Behavior \& Evolution, 1, 500-518.

JaEGer, R. G., \& HaIluman, J. P. (1973). Effects of intensity on the phototactic responses of adult anuran amphibians: A comparative survey. Zeitschrift fiur Tierpsychologie, 33, 352-407.

JAEGER, R. G., \& HaILMAN, J. P. (1976). Ontogenetic shift of spectral phototactic preferences in anuran tadpoles. Joumal of Comparative \& Physiological Psychology, 90, 930-945.

Johnson, J. A., \& BRodIE, E. D., JR. (1975). The selective advantage of the defensive posture of the newt, Taricha granulosa. American Midland Naturalist, 93, 139-148.

KIMBLE, D. P., \& RAY, R. S. (1965). Reflex habituation in Rana pipiens. Animal Behaviour, 13, 530-533.

KLEEREKOPER, H., Sibabin, K. (1959). A study on hearing in frogs (Rana pipiens and Rana clamitans). Zeitschrift für Vergleichende Physiologie, 41, 490-499.

KLUGE, A. G. (1981). The life history, social organization, and parental behavior of Hyla rosenbergi Boulenger, a nest-building gladiator frog. In Miscellaneous Publications of the Museum of Zoology of the University of Michigan (No. 160, pp. 1-170). Ann Arbor, MI: University of Michigan.

KruSe, K. C., STONE, B. M. (1984). Largemouth bass (Micropterus salmoides) learn to avoid feeding on toad (Bufo) tadpoles. Animal Behaviour, 32, 1035-1039.

KURODA, R. (1933). Studies on visual discrimination in the tortoise Clemmys japonica. Acta Psychologica (Keijo), 2, 31-59.

Laming, P. R., Austin, M. (1981). Cardiac responses of the anurans Bufo bufo and Rana pipiens during behavioral arousal and fright. Comparative Biochemistry \& Physiology, 68A, 515-518.

LANDRETH, H. F., FERGuSON, D. E. (1968). The sun compass of Fowler's toad, Bufo woodhousei fowleri. Behaviour, 30, 27-43.

LichT, L. E. (1986). Comparative escape behavior of sympatric Rana curora and Rana pretiosa. American Midland Naturalist, 115, 239-247.

LOOP, M. S. (1970). The effects of feeding experience on the response to prey-object extracts in rat snakes. Psychonomic Science, 21, 189-190.

Loop, M. S. (1976). Auto-shaping-A simple technique for teaching a lizard to perform a visual discrimination task. Copeia, 574-576.
LOop, M. S., \& ScoviLLE, S. A. (1972). Response of newborn Eumeces inexpectatus to prey-object extracts. Herpetologica, 28, 254-256.

LORENZ, K. Z. (1969). Innate bases of learning. In K. H. Pribram (Ed.), On the biology of leaming (pp. 13-93). New York: Harcourt, Brace \& World.

LUTHARDT, G., \& RoTH, G. (1979). The influence of prey experience on movement pattern preference in Salamandra salamandra (L.). Zeitschrift für Tierpsychologie, 51, 252-259.

LuTHARDT, G., RoTH, G. (1983). The interaction of the visual and olfactory systems in guiding prey catching behaviour in Salamandra salamandra (L.). Behaviour, 83, 69-79.

LUTHARDT-LAIMER, G. (1983). Ontogeny of preferences to visual prey stimulus parameters in salamanders. Journal of Herpetology, 17, 221-227.

LUTHARDT-LAIMER, G., \& Roth, G. (1983). Reduction of visual inhibition to stationary prey by early experience in Salamandra salamandra (L). Zeitschrifi fur Tierpsychologie, 63, 294-302.

Madison, D. M. (1975). Intraspecific odor preferences between salamanders of the same sex: Dependence on season and proximity of residence. Canadian Joumal of Zoology, 53, 1356-1361.

MaGNusson, W. E. (1980). Hatching and crèche formation by Crocodylus porosus. Copeia, 359-362.

MaHmoud, I. Y., \& LAVENDA, N. (1969). Establishment and eradication of food preferences in red-eared turtles. Copeia, 298-300.

MarCELuNI, D. (1977). Acoustic and visual display behavior of gekkonid lizards. American Zoologist, 17, 251-260.

MARCHISIN, A., \& ANDERson, J. D. (1978). Strategies employed by frogs and toads (Amphibia, anura) to avoid predation by snakes (Reptilia, serpentes). Joumal of Herpetology, 12, 151-155.

MARTOF, B. S. (1962). Some observations on the role of olfaction among salientian amphibia. Physiological Zoology, 35, 270-272.

Mason, J. R., Meredith, M., \& Stevens, D. A. (1981). Odorant discrimination by tiger salamanders after combined olfactory and vomeronasal nerve cuts. Physiology \& Behavior, 27, 125-132.

Mason, J. R., \& MORTON, T. H. (1982). Temporary and selective anosmia in tiger salamanders (Ambystoma tigrinum) caused by chemical treatment of the olfactory epithelium. Physiology \& Behavior, 29, 709-714.

Mason, J. R., STEVENS, D. A. (1981). Discrimination and generalization among reagent grade odorants by tiger salamanders (Ambystoma tigrinum). Physiology \& Behavior, 26, 647-653.

Mason, J. R., SteVENS, D. A., \& RABIN, M. D. (1980). Instrumentally conditioned avoidance by tiger salamanders (Ambystoma tigrinum) to reagent grade odorants. Chemical Senses, 5, 99-105.

McGill, T. E. (1960). Response of the leopard frog to electric shock in an escape-learning situation. Journal of Comparative \& Physiological Psychology, 53, 443-445.

MCVey, M. E., Zahary, R. G., Perry, D., \& MacDougal, J. (1981). Territoriality and homing behavior in the poison dart frog (Dendrobates pumilio). Copeia, 1-8.

Melcer, T., \& Chiszar, D. (1989a). Strike-induced chemical preferences in prairie rattlesnakes (Crotalus viridis). Animal Learning \& Behavior, 17, 368-372.

Melcer, T., ChISZAR, D. (1989b). Striking prey creates a specific chemical search image in rattlesnakes. Animal Behaviour, 37, 477-486.

MikulKa, P., Hughes, J., \& AGGeruP, G. (1980). The effect of pretraining procedures and discriminative stimuli on the development of food selection behaviors in the toad (Bufo terrestris). Behavioral \& Neural Biology, 29, 52-62.

MikulKa, P., Vaughan, P., \& Hughes, J. (1981). Lithium chlorideproduced prey aversion in the toad (Bufo americanus). Behavioral \& Neural Biology, 33, 220-229.

MILleR, R. R., \& BERK, A. M. (1977). Retention over metamorphosis in the African claw-toed frog. Joumal of Experimental Psychology: Animal Behavior Processes, 3, 343-356.

Miller, R. R., Berk, A. M., \& SPringer, A. D. (1974). Acquisition and retention of active avoidance in Xenopus laevis. Bulletin of the Psychonomic Society, 3, 139-141.

MLYNARSKI, M. (1951). The ability to recognize complete forms from their fragments in the water tortoises: Emydinae. Bulletin Interna- 
tional de l'Académie Polonaise des Sciences er des Lettres: Classe des Sciences Mathematiques et Naturelles. Série B: Sciences Naturelles (11), 253-270.

MOORE, A. R., Welch, J. C. (1940). Associative hysteresis in larval Amblystoma. Journal of Comparative Psychology, 29, 283-292.

MoRRIs, D. D., \& LOOP, M. S. (1969). Stimulus control of prey attack in naive rat snakes: A species duplication. Psychonomic Science, 15, 141-142.

MUNN, N. L. (1940). Learning experiments with larval frogs: A preliminary report. Journal of Comparative Psychology, 29, 97-108.

Muntz, W. R. A. (1962). Effectivenss of different colors of light in releasing positive phototactic behavior of frogs, and a possible function of the retinal projection to the diencephalon. Joumal of Neurophysiology, 25, 712-720.

Murillo, N. R., Diercks, J. K., \& Capaldi, E. J. (1961). Performance of the turtle, Pseudemys scripta troostii, in a partial-reinforcement situation. Joumal of Comparative \& Physiological Psychology, 54, 204-206.

MuRPHY, P. A. (1981). Celestial compass orientation in juvenile American alligators (Alligator mississippiensis). Copeia, 638-645.

MUSHINSKY, H. R. (1976). Ontogenetic development of microhabitat preference in salamanders: The influence of early experience. Copeia, 755-758.

MUSHINSKY, H. R., \& Lotz, K. H. (1980). Chemoreceptive responses of two sympatric water snakes to extracts of commonly ingested prey species. Ontogenetic and ecological considerations. Journal of Chemical Ecology, 6, 523-535.

NetTing, M. G., \& Goin, C. J. (1945). The cricket-frog of peninsular Florida. Quarterly Journal of Florida Academy of Sciences, 8, 304-310.

NorthCutt, R. G., Heath, J. E. (1973). T-maze behavior of the tuatara (Sphenodon punctatus). Copeia, 617-620.

O'Connell, B., Chiszar, D., \& SMITH, H. M. (1981). Effect of poststrike disturbance on strike-induced chemosensory searching in the prairie rattlesnake (Crotalus v. viridis). Behavioral \& Neural Biology, 32, 343-349.

O'Connell, B., Chiszar, D., \& SiTh, H. M. (1983). Strike-induced chemosensory searching in prairie rattlesnakes (Crotalus viridis) during daytime and at night. Joumal of Herpetology, 17, 193-196.

O'HARA, R. K., \& BlAUSTEIN, A. R. (1982). Kin preference behavior in Bufo boreas tadpoles. Behavioral Ecology \& Sociobiology, 11, 43-49.

Pert, A., \& Bitterman, M. E. (1969). A technique for the study of consummatory behavior and instnumental learning in the turtle. American Psychologist, 24, 258-261.

PITKIN, R. B., \& Tilley, S. G. (1982). An unusual aggregation of adult Notophthalmus viridescens. Copeia, 185-186.

Pooley, A. C., GAns, C. (1976). The Nile crocodile. Scientific American, 234(4), 114-124.

Powell, R. W. (1967). Avoidance and escape conditioning in lizards. Psychological Reports, 20, 583-586.

PowelL, R. W. (1968). A readily-available test chamber used in the study of shuttle escape and avoidance in the lizard Anolis sagrei. Psychological Record, 18, 585-590.

Powell, R. W., \&ANTOR, H., JR. (1969). Failure to obtain oneway shuttle avoidance in the lizard Anolis sagrei. Psychological Record, 19, 623-627.

Powell, R. W., PECK, K. (1970). Instrumental aversive conditioning in the Skink Eumeces Inexpectatus studied with two test chambers. Psychonomic Science, 18, 263-264.

Pritz, M. B., Bass, A. H., \& Northcutt, R. G. (1973). A simple apparatus and training techniques for teaching turtles to perform a visual discrimination task. Copeia, 181-183.

RAY, A., JR. (1970). Instrumental avoidance learning by the tiger salamander Ambystoma tigrinum. Animal Behaviour, 18, 73-77.

ReZnick, D., Sexton, O. J., \& MANTIS, C. (1981). Initial prey preferences in the lizard Sceloporus malachiticus. Copeia, 681-686.

Richardson, A. M., Julian, S. M. (1974). Avoidance learning in the lizard Dipsosaurus dorsalis. Psychological Reports, 35, 35-40.

Richmond, N. D. (1947). Life history of Scaphiopus holbrookii holbrookii (Harlan). Part 1: Larval development and behavior. Ecology, 28, 53-67.

Roth, G., LUTHARDT, G. (1980). The role of early sensory experience in the prey catching responses of Salamandra salamandra to stationary prey. Zeitschrifi fur Tierpsychologie, 52, 141-148.

Salthe, S. N., Mecham, J. S. (1974). Reproductive and courtship patterns. In B. Lofts (Ed.), Physiology of amphibia (Vol. 2, pp. 309521). New York: Academic Press.

SCHAEFFER, A. A. (1911). Habit formation in frogs. Journal of Animal Behavior, 1, 309-335.

Schall, J. J., Pianka, E. R. (1980). Evolution of escape behavior diversity. American Naturalist, 115, 551-566.

SCHMIDT, R. S. (1966). Central mechanisms of frog calling. Behaviour, 26, 251-285.

SCHNEIDER, C. W. (1968). Avoidance learning and the response tendencies of the larval salamander Ambystoma punctatum to photic stimulation. Animal Behaviour, 16, 492-495.

SCHÖNE, H. (1964). Release and orientation of behaviour and the role of learning as demonstrated in crustacea. Animal Behaviour, 12 (Suppl. 1), 135-144.

Segal, M., Hershkowitz, M., Samuel, D., Bitterman, M. E. (1971). Rapid modification of amphibian behavior by punishment. Psychonomic Science, 24, 249-250.

Sexton, O. J. (1964). Differential predation by the lizard, Anolis carolinensis, upon unicoloured and polycoloured insects after an interval of no contact. Animal Behaviour, 12, 101-110.

Sexton, O. J., Hoger, G., ORTleb, E. (1966). Anolis carolinensis: Effects of feeding on reaction to aposematic prey. Science, 153, 1140.

Sheffield, L. P., LAW, J. H., \& Burghardt, G. M. (1968). On the nature of chemical food sign stimuli for newborn snakes. Communications in Behavioral Biology, 2, 7-12.

SIGMUND, W. R. (1983). Female preference for Anolis carolinensis males as a function of dewlap color and background coloration. Journal of Herpetology, 17, 137-143.

SMITH, R. G., JR. (1948). A preliminary investigation of color discrimination in the Florida cricket frog, Acris gryllus dorsalis (Harlan). Journal of Psychology, 25, 171-183.

SPIGEL, I. M., \& Elus, K. R. (1965). Brightness preference in the frog. Perceptual \& Motor Skills, 21, 367-370.

SternTHAL, D. E. (1974). Olfactory and visual cues in the feeding behavior of the leopard frog (Rana pipiens). Zeitschrift fur Tierpsychologie, 34, 239-246.

Stimac, K., Radcliffe, C. W., Chiszar, D. (1982). Prey recognition learning by red spitting cobras, Naja mossambica pallida. Bulletin of the Psychonomic Society, 19, 187-188.

SuboskI, M. D. (1988). Acquisition and social communication of stimulus recognition by fish. Behavioural Processes, 16, 213-244.

Suboskı, M. D. (1989). Recognition learning in birds. Perspectives in Ethology, 8, 137-171.

Suboski, M. D. (1990). Releaser-induced recognition learning. Psychological Review, $97,271-284$.

Suboski, M. D., Bain, S., Carty, A. E., McQuoid, L. M., Seelen, M. I., SEIFERT, M. (1990). Alarm reaction in acquisition and social transmission of simulated-predator recognition by zebra danio fish (Brachydanio rerio). Joumal of Comparative Psychology, 104, 101-112.

SwIEżAWSKA, K. (1949). Colour-discrimination of the sand lizard Lacerta agilis L. Bulletin Intermational de l'Académie Polonaise des Sciences et des Lettres, Classe des Sciences Mathematiques et Naturelles, Série B: Sciences Naturelles (II), 1-20.

Theios, J., \& DUNAWAY, J. E. (1964). One-way versus shuttle avoidance conditioning. Psychonomic Science, 1, 251-252.

Thompson, P. A., Boice, R. (1975). Attempts to train frogs: Review and experiments. Journal of Biological Psychology, 17, 3-13

THORNDIKE, E. L. (1935). The psychology of wants, interests and attitudes. New York: Appleton-Century.

THORPE, W. H. (1963). Learning and instinct in animals (2nd ed.). Cambridge: Harvard University Press.

TinkLePaUGH, O. L. (1932). Maze learning of a turtle. Joumal of Comparative Psychology, 13, 201-206.

Townsend, D. S., Stewart, M. M., Pough, F. H. (1984). Male parental care and its adaptive significance in a neotropical frog. Animal Behaviour, 32, 421-431

TUtTlE, M. D., TAFT, L. K., RYAN, M. J. (1982). Evasive behaviour of a frog in response to bat predation. Animal Behaviour, 30, 393-397. 
VAN BERGEIJK, W. A. (1967). Anticipatory feeding behaviour in the bullfrog (Rana catesbeiana). Animal Behaviour, 15, 231-238.

Van ZaNDT Brower, J., \& Brower, L. P. (1962). Experimental studies of mimicry 6. The reaction of toads (Bufo terrestris) to honeybees (Apis millifera) and their dronefly mimics (Eristalis vinetorum). American Naturalist, 96, 297-307.

VoN UExKüLL, J. (1957). A stroll through the worlds of animals and men (C. H. Schiller, trans.). In C. H. Schiller (Ed.), Instinctive behavior (pp. 5-80). New York: International Universities Press.

WaLdman, B. (1981). Sibling recognition in toad tadpoles: The role of experience. Zeitschrift für Tierpsychologie, 56, 341-358.

WALDMAN, B. (1984), Kin recognition and sibling association among wood frog (Rana sylvatica) tadpoles. Behavioural Ecology \& Sociobiology, 14, 171-180.

Waldman, B. (1986). Preference for unfamiliar siblings over familiar nonsiblings in American toad (Bufo americanus) tadpoles. Animal Behaviour, 34, 48-53.

Wassersug, R., Hessler, C. M. (1971). Tadpole behaviour: Aggregation in larval Xenopus laevis. Animal Behaviour, 19, 386-389.

WELLS, K. D. (1977). The social behaviour of anuran amphibians. Animal Behaviour, 25, 666-693.

WEYGOLDT, P. (1980). Complex brood care and reproductive behavior in captive poison-arrow frogs, Dendrobates pumilio O. Schmidt. Behavioural Ecology \& Sociobiology, 7, 329-332.

Whitney, C. L., \&ReBs, J. R. (1975). Mate selection in Pacific tree frogs. Nature, 225, 325-326.

WIENS, J. A. (1970). Effects of early experience on substrate pattern selection in Rana aurora tadpoles. Copeia, 543-548.
WiENS, J. A. (1972). Anuran habitat selection: Early experience and substrate selection in Rana cascadae tadpoles. Animal Behaviour, 20, 218-220.

WILDE, W. S. (1938). The role of Jacobson's organ in the feeding reaction of the common garter snake, Thamnophis sirtalis sirtalis (Linn.). Journal of Experimental Zoology, 77, 445-465.

Williams, E. E., \& RAND, A. S. (1977). Species recognition, dewlap function and faunal size. American Zoologist, 17, 261-270.

WoODRUFF, D. S. (1977). Male postmating brooding behavior in three Australian pseudophryne (Anura: Leptodactylidae). Herpetologica, 33, 296-303.

YAREMKo, R. M., Boice, R., \& Thompson, R. W. (1969). Classical and avoidance conditioning of the nictitating membrane in frogs (Rana pipiens) and toads (Bufo Americanus). Psychonomic Science, 16, 162-164.

YAREMKo, R. M., JeTte, J., \& UtTer, W. (1974). Further study of avoidance conditioning in toads. Bulletin of the Psychonomic Society, 3, 340-342.

YERKES, R. M. (1903). The instincts, habits, and reactions of the frog. Harvard Psychological Studies, 1, 579-638.

Zavala, A. (1968). Classical conditioning in frogs (Rana pipiens). Journal of Herpetology, 1, 83-85.

(Manuscript received January 16, 1991; revision accepted for publication October 10, 1991.) 